\title{
MODELING AND OPTIMIZATION OF END MILLING MACHINING PROCESS
}

\author{
WDS.MILTON.PONNALA ${ }^{1}$, K .L .N. MURTHY ${ }^{2}$ \\ ${ }^{1}$ M.Tech (student), ${ }^{2}$ Associate Professor, Mechanical Engineering Department, GIET, Andhra Pradesh, India, \\ wdsmiltonponnala@gmail.com,kln_m@rediffmail.com
}

\begin{abstract}
Generally in any manufacturing industry, a human process planner selects the machining parameters based on his expertise or from data handbooks; they do not represent the optimal values. The optimization process involves the optimal selection of machining parameters such as cutting speed, feed and depth of cut, subjected to practical constraints of surface finish, tool wear, dimensional accuracy and machine tool capabilities. Several researches have used different techniques in literature to optimize machining process by considering a machining problem as single objective optimization problem. However a machining problem should be treated as a multi objective problem as it involves two conflicting objectives: machining time and production cost. In such problems there cannot be single optimal solution. To get all optimal solutions, a multi objective optimization method called Non-dominated Sorting Genetic Algorithm (NSGA) is proposed in the project work. In the first part of the present work, mathematical relationships between input and output parameters have been developed by Response Surface Methodology (RSM). Consequently there have been solved to get the optimal values. The general second order composite rotatable design is used in planning and modeling the experiments. The experiments were conducted on the general purpose milling machine using a 60mm*60mm*40mm block (AISI 1040steel).In the second part a multi optimization algorithm called non dominated sorting genetic algorithm was used to retrieve all set of optimum values. In NASA, the non-dominated sorting procedure is used to bring forth the good points of correct population and stable subpopulations of good points are maintained by Niche method. The present work enables the industries to have the optimum values of the milling process variables and conducting the process can be automated based on optimal values.
\end{abstract}

Index Terms: AISI 1040steel, Non-dominated Sorting Genetic Algorithm (NSGA), Optimization, Response Surface Methodology (RSM), and Multi Optimization Algorithm etc...

\section{INTRODUCTION}

Milling is the process of cutting away material by feeding a work piece past a rotating multiple tooth cutter. The cutting action of the many teeth around the milling cutter provides a fast method of machining. The machined surface may be flat, angular, or curved. The surface may also be milled to any combination of shapes. The machine for holding the work piece, rotating the cutter, and feeding it is known as the milling machine.

\subsection{Methods Of Milling}

\subsubsection{Up Milling}

Up milling is also referred to as conventional milling. The direction of the cutter rotation opposes the feed motion. For example, if the cutter rotates clockwise, the workpiece is fed to the right in up milling.

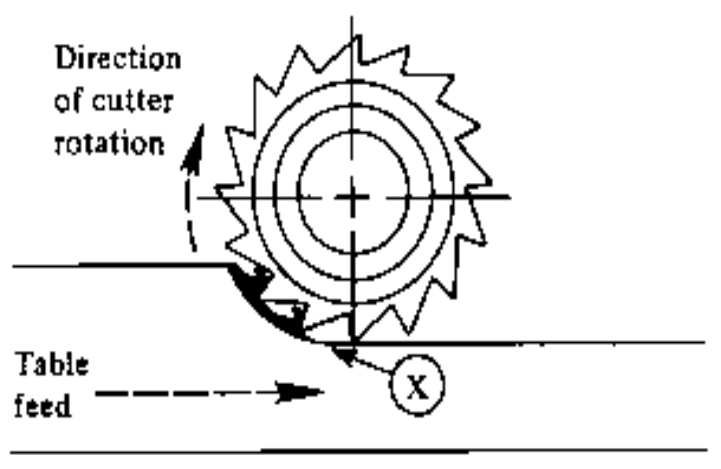

Fig.1.2.Up Milling machining process

\subsubsection{Down Milling}

Down milling is also referred to as climb milling. The direction of cutter rotation is same as the feed motion. For example, if the cutter rotates counterclockwise, the workpiece is fed to the right in down milling. 


\subsubsection{End milling}

An end mill is one of the indispensable tools in the milling processing. The end mill has edges in the side surface and the bottom surface. The fundamental usage is that the end mill is rotated, and makes a plane of a material in the right-and-left direction or a plane of a bottom side of the end mill. We can make various shapes of mechanical parts with the end mill.

An endmill is a type of milling cutter a cutting tool used in industrial milling applications. It is distinguished from the drill bit in its application, geometry, and manufacture. While a drill bit can only cut in the axial direction, a milling bit can generally cut in all directions, though some cannot cut axially.Endmills are used in milling applications such as profile milling, tracer milling, face milling, and plunging.

\section{Design criteria}

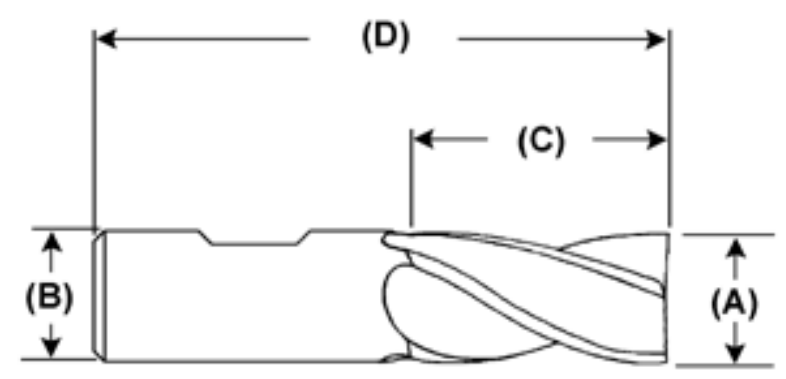

$$
\begin{aligned}
& \text { A-millsize or cutting diameter } \\
& \text { B - shank diameter } \\
& \text { C - length of cut or flute length } \\
& \text { D - overall length }
\end{aligned}
$$

\section{DESCRIPTION OF PRESENT PROBLEM}

End milling hardened steel is an economical method to generate a high quality machined surface. Being a complex process, it is very difficult to determine the optimal parameters for improving cutting performance. A vast array of research is carried out to study the influence of the various factors effecting the machining performance and productivity. Surface finish and MT is the most important out put parameters in any machining process. These out put parameters are influenced numerous process parameters in endmilling. Form the literature survey it is found that the parameters such as depth of cut, feed rate, cutting speed and step over has considerable influence on surface roughness and machining time. To study the influence of these process parameters, an experiment is conducted using Response surface method (RSM). RSM comprises a group of statistical techniques for empirical model building and model exploration. The response surface methodology is practical, economical and relatively easy for use. The experimental data were utilized to build mathematical model for first and second order model, by regression method. A response or output function is related to a number of input variables that affect it. The variables studied will depend on the specific field of application. The response surface method can substantially reduce the total number of experiments often carried out randomly and it is an adequate and reliable method to measure the true mean response of interest.

The experimental study was carried out in wet cutting conditions on a DECKEL MAHO DMU 60 P five-axis,highspeed CNC milling machine equipped with a maximum spindle speed of 12,000 rpm, feed rate of $10 \mathrm{~m} / \mathrm{min}$ and a 15 $\mathrm{kW}$ drive motor. CNC part programs for tool paths were created. The workpiece material used was AISI 1040 steel in the form of a $60 \mathrm{mmX} 60 \mathrm{mmX} 40 \mathrm{~mm}$ block. A total of 30 experiments were conducted according to the central composite design developed by RSM. The corresponding surface roughness and machining time for each experiment is calculated and recorded.

The present optimization problem involves in two major objective functions. The first objective is to minimize Surface roughness ( $\mathrm{Ra}$ ) and the second objective is to minimize (MT). When the optimization problem involves in more than one objective function, the task of finding one or more optimum solutions is known as Multi-objective optimization.

The present problem involves in two major objectives. Optimization can not be done to only one objective, when another objective is also important. Different solutions may produce conflicting scenarios between the two objectives. A solution, which is excellent with respect to one objective, requires a compromise in the other objective. This prohibits one to choose a solution, which is optimal with respect to only one objective, which makes the two objectives conflicting. The surface roughness and machining time are proportional to each other. If surface roughness increases then machining time also increase and vice versa. Conventional optimization problem transforms a multi objective optimization problem into single objective optimization problem. A simple method of converting this multi-objective is to form a composite objective function as a weighted sum of the objectives, where a weight for an objective is assigned, which is proportional to the performance factor of that particular objective. When a composite function is optimized, in most cases it is possible to obtain only one optimal solution in a single simulation. Evolutionary algorithms (EA) are non-classical optimization methods, which mimic nature's evolutionary principles to drive its search towards an optimal solution. One of the most striking differences to classical search and optimization algorithms is that EAs use population solutions in each in iteration, instead of single solution. Since population of solution is proposed in each iteration, the out come of EA is also a population of solutions. The ability 
of an EA to find multiple optimal solutions in one simulation run makes EAs unique in solving multi-objective optimization problems.

\section{RESPONSE SURFACE METHODOLOGY}

Response surface methodology or RSM is a collection of mathematical and statistical techniques that are useful for the modeling and analysis of problems in which response of interest is influenced by several variables and the objective is to optimize this response. For example, suppose that a chemical engineer wishes to find the levels of temperature (x1) and pressure (x2) that maximizes the yield (y) of a process. The process yield is a function of the levels of temperature and pressure, say

$$
Y=f(x 1, x 2)+\varepsilon
$$

Where $\varepsilon$ represents the noise or error observed in the process $y$. if we denote the expected response by

$$
E(y)=f f(x 1, x 2)=\eta,
$$

then the surface is represented by

$$
\eta=f(x 1, x 2)
$$

is called response surface.We usually represent the response surface graphically, such as in fig 4.1, where $\eta$ is plotted versus the levels of $x 1, x 2$. To help visualize the shape of a response surface, we often plot the contours of the response surface as shown in fig 4.2. in the contour plot, lines of constant response are drawn in the $\mathrm{x} 1, \mathrm{x} 2$ plane. Each contour corresponds to a particular height of the response surface.

$k$

In most RSM problems, the form of the relationship between the response and the independent variables is unknown. Thus, the first step in RSM is to find a suitable approximation for the true functional relationship between $y$ and the set of independent variables is employed. If the response is well modeled by a linear function of the independent variables, then the approximating function is the first order model.

$$
\mathrm{Y}=\beta 0+\beta 1 \times 1+\beta 2 \times 2+--------------+\beta \mathrm{kxk}+\varepsilon
$$

If there is curvature in the system, then a polynomial of higher degree must be used, such as the second order model. $k$

$$
\mathrm{Y}=\beta 0+\square \mathrm{j} \square 1 \square \mathrm{j} \times \mathrm{j} \square^{k} \square \square \text { i } \square \mathrm{ij} \text { jxi x j } \square \text { x j } \square 1 \square \text { ij j }
$$

Almost all RSM problems use one or both of these models. Of course it is unlikely that a polynomial model will be a reasonable approximation of the true function relationship over the entire space of the independent variables, but for a relatively small reason, they usually work quite
well.The method of least squares is used to estimate the parameters in the approximating polynomials. The RSM is then performed using the fitted surface. If the fitted surface is the adequate approximation, of the true response function, then analysis of the fitted surface will be approximately equal to analysis of the actual system. The model parameters can be estimated most effectively if proper experimental design is used to collect the data. Designs for fitting response surfaces are called response surface results. RSM is a sequential procedure. Often, when we are at a point on the response surface that is remote from the optimum, such as the current operating condition in the fig 4.2 , there is little curvature in the system and the first order model will be appropriate. Our objective here is to leave the experimenter rapidly and efficiently along the path of improvement towards the general vicinity of the optimum. Once the reason of the optimum has been found, a more elaborate model, such as second order model, may be employed, and an analysis will be performed to locate optimum. From the fig 4.3 we see that the analysis of response surface can be thought of as 'climbing a hill', where the top of the hill represents the point of maximum response. If the true optimum is a point of minimum response, then we think of 'descending into a valley'.The eventual objective of RSM is to determine the optimum operating conditions for the system or to determine a region of the factor space in which operating requirements are satisfied.

\subsection{Designs For Fitting First Order Model}

Suppose we wish to fit the first order model in k variables

$$
\mathrm{Y}=\beta 0+\square \mathrm{i} \square 1 \square \text { ixi } \square \square
$$

There is a unique class of designs that minimize the variance of the regression coefficients $(\beta \mathrm{i})$. These are the orthogonal first-order designs. A first- order design is orthogonal if the off-diagonal elements of the (X1X) matrix are all zero. This implies that the cross products of the columns of the $\mathrm{X}$ matrix sum to zero. The class of orthogonal first-order designs includes the $2 \mathrm{k}$ factorial and fractions of the $2 \mathrm{k}$ series in which main effects are not aliased with each other. In using these designs, we assume that the low and high levels of the $\mathrm{k}$ factors are coded to usual \pm 1 levels. The $2 \mathrm{k}$ designs do not afford an estimate of the experimental error unless some runs are replicated. A common method of including replication in the $2 \mathrm{k}$ designs is to augment the design with several observations at the center (the point $x i=0, i=1,2,3,----, k$ ). The addition of center points to the designs does not influence the $(\beta i)$ for $i \geq 1$, but the estimate of $\beta 0$ becomes the grand average of all observations. Furthermore, the addition of center points does not alter the orthogonally property of the design. 


\subsection{Designs For Fitting Second Order Model}

Central composite design is the most popular class of designs just for fitting second order models. Generally the CCD consists of a $2 \mathrm{k}$ factorial (or fractional factorial of resolution $\mathrm{V}$ ) with $\mathrm{nf}$ runs, $2 \mathrm{k}$ axial or star runs and nc center runs. Figure 4.4 shows the $\mathrm{CCD}$ for $\mathrm{k}=2$ and $\mathrm{k}=3$ factors. The practical deployment of a CCD often arises through sequential experimentation. That is the $2 \mathrm{k}$ has been used to fit a first model, this model has exhibited lack of fit and the axial runs are then added to allow the quadratic terms to be incorporated in to the model. The CCD is a very efficient design for fitting the second order model. There are two parameters in the design that must be specified, the distance $\alpha$ of the axial runs from the design center and the number of center points nc. We now discuss the choice of these two parameters.

\section{NONDOMINATED SORTING GENETIC}

\section{ALGORITHEM}

Many real-world design or decision making problems involve simultaneous optimization of multiple objectives. In principle, multi objective optimization is very different than the single objective optimization. In single objective optimization, one attempts to obtain the best design or decision, which is usually the global minimum or the global maximum depending on the optimization problem is that of minimization or maximization. In the case of multiple objectives, there may not exist one solution which is best (global minimum or maximum) with respect to all objectives. In a typical multi objective optimization problem, there exists a set of solutions which are superior to the rest of solutions in the search space when all objectives are considered but are inferior to other solutions in the space in one or more objectives. These solutions are known as Pareto-optimal solutions or non dominated solutions (ChankongandHaimes1983;Hans1988). The rest of the solutions are known as dominated solutions. Since none of the solutions in the non dominated set is absolutely better than any other, any one of them is an acceptable solution. The choice of one solution over the other requires problem knowledge and a number of problem related factors. Thus, one solution chosen by a designer may not be acceptable to another designer or in a changed environment. Therefore, in multi objective optimization problems, it may be useful to have a knowledge about alternative Pareto-optimal solutions.

One way to solve multi objective problems is to scalarize the vector of objectives into one objective by averaging the objectives with a weight vector. This process allows a simpler optimization algorithm to be used, but the obtained solution largely depends on the weight vector used in the scalarization process. Moreover, if available, a decision maker may be interested in knowing alternate solutions. Since genetic algorithms (GAs) work with a population of points, a number of Pareto-optimal solutions may be captured using GAs. A nearly GA application on multi objective optimization by Schaffer (1984) opened a new avenue of research in this field. Though his algorithm, VEGA, gave encouraging results, it suffered from biasness towards some Pareto- optimal solutions. A new algorithm, Non dominated Sorting Genetic Algorithm (NSGA), is presented in this paper based on Goldberg's suggestion (Goldberg1989). This algorithm eliminates the bias in VEGA and there by distributes the population over the entire Pareto- optimal regions. Although there exist two other implementations (Fonesca and Fleming 1993; Horn, Nafpliotis, and Goldberg 1994) based on this idea, NSGA is different from their working principles, as explained below.

In the remainder of the paper, we briefly describe difficulties of using three common classical methods to solve multi objective optimization problems. A brief introduction to Schaffer's VEGA and its problems are outlined. Thereafter, the non dominated sorting GA is described and applied to three two-objective test problems. Simulation results show that NSGA performs better than VEGA on these problems. A number of extensions to this work is also suggested.

\subsection{Multi Objective Optimization Problem}

A general multi objective optimization problem consists of a number of objectives and is associated With a number of inequality and equality constraints. Mathematically, the problem can be written as follows (Rao1991):

Minimize / Maximize f i (x) i= $1,2, \ldots \ldots . \mathrm{N}$

Subject to

$$
\begin{gathered}
g \mathrm{j}(\mathrm{x})<=0 \quad \mathrm{j}=1,2, \ldots \mathrm{J} \\
\mathrm{hk}(\mathrm{x})=0 \quad \mathrm{k}=1,2, \ldots . \mathrm{K}
\end{gathered}
$$

\subsection{GA Implementation}

As early as in 1967, Rosenberg suggested, but did not simulate, a genetic search to the simulation of the genetics and the chemistry of a population of single-celled organisms with multiple properties or objectives (Rosenberg1967). The first practical algorithm, called Vector Evaluated Genetic Algorithm (VEGA), was developed by Schaffer in 1984 (Schaffer 1984). One of the problems with VEGA, as realized by Schaffer himself, is its bias towards some Pareto-optimal solutions.

Later, Goldberg suggested another non dominated sorting procedure to overcome this weakness of VEGA (Goldberg 1989). Our algorithm, Non dominated Sorting Genetic Algorithm (NSGA), is developed based on this idea. There exists atleast two other studies, different from our algorithm, based on Goldberg's idea. In the rest of this section, we discuss the merits and demerits of VEGA and NSGA, and the differences between NSGA and the two other recent implementations. 


\subsubsection{Schaffer's VEGA}

Schaffer modified the simple tripartite genetic algorithm by performing independent selection cycles according to each objective. He modified Grefenstette's GENESIS program (Schaffer 1984) by creating a loop around the traditional selection procedure so that the selection method is repeated for each individual objective to fill up a portion of the mating pool. Then the entire population is thoroughly shuffled to apply cross over and mutation operators. This is performed to achieve the mating of individuals of different sub population groups. The algorithm worked efficiently for some generations but in some cases suffered from its bias towards some individuals or regions. The independent selection of specialists resulted in speciation in the population. The out come of this effect is the convergence of the entire population towards the individual optimum regions after a large number of generations. Being a decision maker, we may not like to have any bias towards such middling individuals, rather we may want to find as many non dominated points as possible.

Schaffer tried to minimize this speciation by developing two heuristics |the non dominated selection heuristic (a wealth redistribution scheme), and the mate selection heuristic (across breeding scheme) (Schaffer 1984). In the non dominated selection heuristic, dominated individuals are penalized by subtracting a small fixed penalty from their expected number of copies during selection. Then the total penalty for dominated individuals was divided among the non dominated individuals and was added to their expected number of copies during selection. But this algorithm failed when the population has very few non dominated individuals, resulting in a large fitness value for those few non dominated points, eventually leading to a high selection pressure. The mate selection heuristic was intended to promote the cross breeding of specialists from different sub groups. This was implemented by selecting an individual, as a mate to a randomly selected individual, which has the maximum Euclidean distance in the performance space from its mate. But it failed too to prevent the participation of poorer individuals in the mate selection. This is because of random selection of the rest mate and the possibility of a large Euclidean distance between a champion and a mediocre. Schaffer concluded that the random mate selection is far superior than this heuristic.

One method to minimize speciation is through a nondominated sorting procedure in conjunction with a sharing technique, as suggested by Goldberg (1989). Recently Fonesca and Fleming (1993) and Horn, Nafpliotis, and Goldberg (1994) implemented that suggestion, and successfully applied to some problems. These methods are briefly discussed later. But before that, we discuss our algorithm NSGA which is also developed based on Goldberg's suggestions.

\subsection{Non-Dominating set}

If $\mathrm{S}$ is the non dominating set then following two condition must hold

- Any two solutions of S must be non dominated with respect to each other.

- Any solution not belonging to $\mathrm{S}$ is dominated by at least one member of $\mathrm{S}$.

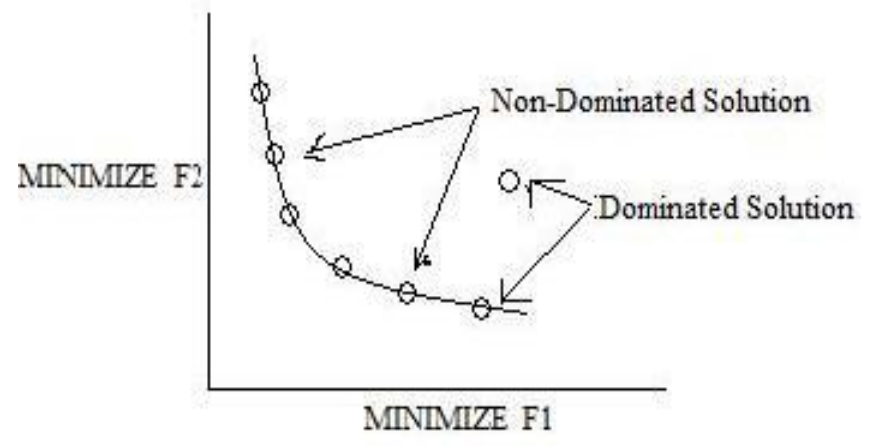

Figure 4.1.Concept of Dominance

\subsection{Identifying Non Dominating set}

There are several approaches proposed in the literature[?]like Naive and Slow approach,Continuously update,Kung et al.s Efficient Method etc.We use continuously update approach to compute non-dominating set of solution.

Identifying Non Dominating set

Step1: Initialize $\mathrm{P}^{I}=\{1\}$. Set solution counter $\mathrm{i}=2$.

Step2: Set $\mathrm{j}=1$.

Step3: Compare solution $\mathrm{i}$ with $\mathrm{j}$ from $\mathrm{P} 0$ for domination.

Step4: If $\mathrm{i}$ dominates $\mathrm{j}$, delete the $\mathrm{j}^{\text {th }}$ member from $\mathrm{P}^{I}$ or update $\mathrm{P}^{I}=$

$\mathrm{P}^{I} \backslash\left\{\mathrm{P}^{I(\mathrm{j})}\right\}$.If $\mathrm{j}<\left|\mathrm{P}^{I}\right|$, increment $\mathrm{j}$ by one and then go to step3.Otherwise

go to step5.Alternatively, if the $\mathrm{j}^{\text {th }}$ member if $\mathrm{P} 0$ dominates i,increment i

by one and then go to step2.

Step5: Insert $\mathrm{i}$ in $\mathrm{P}^{I}$ or Update $\mathrm{P}^{I}=\mathrm{P}^{I}[\{\mathrm{i}\}$.If $\mathrm{i}<\mathrm{N}$, increment i by one

and go to step2.Otherwise ,Stop and declare $\mathrm{P}^{I}$ as the non dominated set.

\subsection{Non-Dominated sorting}

In MOO there are sets of optimal solutions which are NonDominated with respected to each other. Such solutions are arranged in the ascending level of non domination. Procedure to find various level of domination is as follows: 


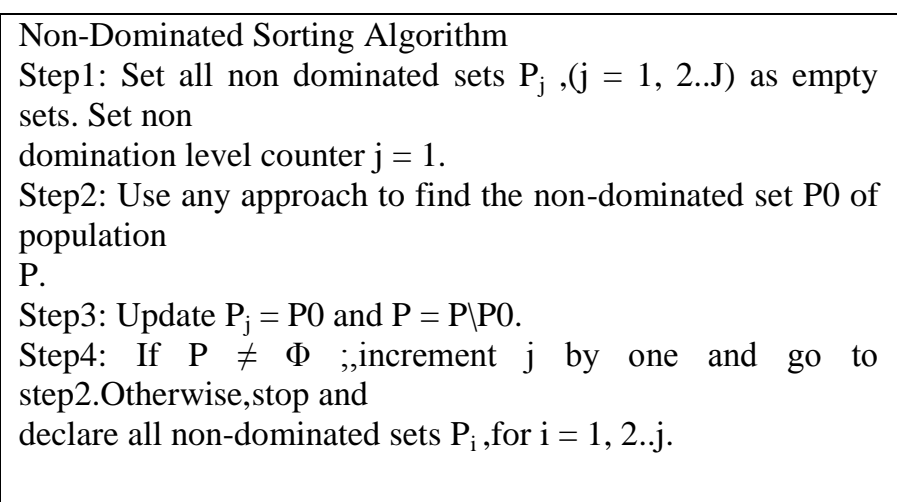

\subsection{Pareto Optimality}

All non dominated solutions are important in the context of Multi Objective Optimization. All these solution are called pareto optimal solution and curve joining such points is called pareto optimal front.

\subsection{Non-Dominated Sorting Genetic Algorithm}

The multi-objective genetic algorithm used in our work is a hybrid genetic algorithm, where the initial population is formed as a combination of first fit ( $80 \%$ of initial population size) and random (20\% of initial population size) instead of entirely random manner. We shall try to find a set of solution as close as possible to the pareto optimal front and as diverse as possible. We have implemented multi-objective genetic algorithm for traffic grooming problem using Non-dominating Sorting Genetic Algorithm (NSGA). The first step of an NSGA is to sort the population $\mathrm{P}$ according to non domination. This classifies the population into a number of mutually exclusive equivalent classes (or non dominated sets) $\mathrm{Pj}$, i.e.,

$$
P=\bigcup_{j=1}^{\rho} P_{j}
$$

Where ${ }^{\rho}$ is the number of non-domination levels.

The fitness assignment procedure begins from the first nondominated set and successively proceeds to dominated sets. Any solution $i$ of the first (or best) non-dominated set is assigned a fitness equal to $\mathrm{Fi}=|\mathrm{P}|$ (population size). This specific value of $|\mathrm{P}|$ is used for a particular purpose. Since all solutions in the first non-dominated set are equally important in terms of their closeness to the pareto optimal front relative to the current population, we assign the same fitness to all of them. Assigning more fitness to a solution belonging to a better non-dominated set ensures a selection pressure toward the pareto optimal front. However, in order to achieve the second goal, diversity among the solutions in a front must also be maintained.The sharing function method is used front-wise. That is, for each solution $\mathrm{i}$ in the front $\mathrm{F}$, the normalized euclidian distance dij from another solution $\mathrm{j}$ in the same front is calculated as follows:

$$
d_{i j}=\sqrt{\sum_{k=1}^{\eta}\left(\frac{x_{k}^{\{i\}}-x_{k}^{\{j\}}}{x_{k}^{\max }-x_{k}^{\min }}\right)^{2}}
$$

where $\eta$ is the number of objectives

$$
S h(d)= \begin{cases}1-\left(\frac{d}{\sigma_{\text {share }}}\right)^{\alpha}, & \text { if } d \leq \sigma_{\text {share }} \\ 0 & \text { otherwise }\end{cases}
$$

The above function takes value between $[0,1]$,depending on the values of $\mathrm{d}$ (euclidean distance) and $\sigma_{\text {share.If } \mathrm{d} \text { is }}$ zero(means two solutions are identical or their distance is zero),

$\mathrm{Sh}(\mathrm{d})=1$. On the other hand, if $\mathrm{d} \geq \sigma$ share (meaning that two solutions are at least a distance of $\sigma_{\text {share away from each }}$ other), $\operatorname{Sh}(\mathrm{d})=0$. This means that two solutions which are a distance of

$\sigma$ share away from each other do not have any sharing effect on each other.Any other distance will have partial effect on each.Hence, we compute niche count (assuming $\_=2$ ) as:

$$
n c_{i}=\sum_{j=1}^{|P|} S h\left(d_{i j}\right)
$$

Niche count of i(nci) is an estimate measure of crowding around a solution $i$. 
The steps of NSGA as given in is as follows

NSGA Fitness Assignment

Step1: Choose the sharing parameter $\sigma$ share and a small positive number $\epsilon$

and initialize $F_{\min }=|P|+\epsilon$. Set front counter $j=1$.

Step2: Classify population $\mathrm{P}$ according to non-domination:

$\left\{\mathrm{P}_{1}, \mathrm{P}_{2}, \mathrm{P} \rho\right\}=\operatorname{Sort}\left(\mathrm{P}_{y}\right)$

Step3: For each $\mathrm{q} \in \mathrm{P}_{\mathrm{j}}$

Step3.1: Assign Fitness $F_{j}^{(q)}=$ Fmin $-E$.

Step3.2: Calculate niche count $\mathrm{nc}_{\mathrm{q}}$ using the above equation among solutions of $\mathrm{P}_{\mathrm{j}}$ only.

Step3.3: Calculate shared fitness $\mathrm{F}_{\mathrm{j}}^{(\mathrm{q})}=\mathrm{F}_{\mathrm{j}}^{(\mathrm{q}) / n c q}$

Step4: $F_{\min }=\min \left(F_{j}^{/(q)}: q \in P_{j}\right)$ and set $j=j+1$.

Step5: If $\mathrm{j} \leq \rho$, to go Step3. Otherwise, the process is complete

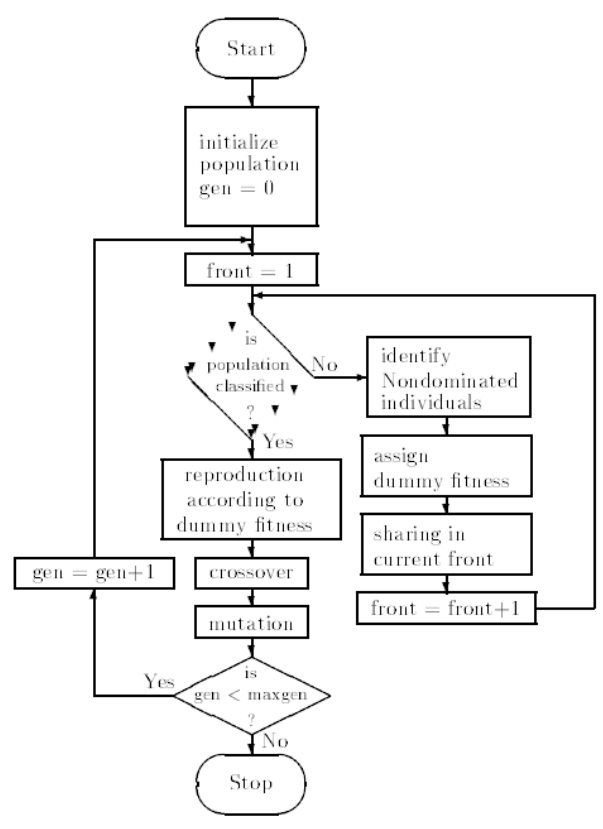

Fig.4.2. NSGA Flow chart

\section{IMPLEMENTATION OF PROPOSED METHODOLOGY}

\subsection{EXPERIMENTAL DETAILS}

\subsubsection{Work piece material, cutting tools and equipment}

The experimental study was carried out in wet cutting conditions on a DECKEL MAHO DMU 60 P five-axis,highspeed CNC milling machine equipped with a maximum spindle speed of $12,000 \mathrm{rpm}$, feed rate of $10 \mathrm{~m} / \mathrm{min}$ and a 15 $\mathrm{kW}$ drive motor. CNC part programs for tool paths were created. The workpiece material used was AISI 1040 steel in the form of a $60 \mathrm{mmX} 60 \mathrm{mmX} 40 \mathrm{~mm}$ block. Tables 1 and 2 provide detailed information on chemical composition and mechanical properties of this AISI 1040 steel. A flat end mill (10mm diameter, 451 helix angle, TiAlN coated solid carbide, 4-flutes) produced by Sandvik(R216.34-10045-AC22N 1620) was used in the tests. The up milling cutting method and compressed cooling oil as the cutting environment were used. The same tool was used until maximum flank wear reached VBmax _ $0.1 \mathrm{~mm}$. The setup of the workpiece and flat end mill is shown in Fig. 6.1.

\subsubsection{Surface roughness measurement}

Surface roughness $\mathrm{Ra}$ was measured using a portable Mitutoyo Surf Test 301. A minimum of 10 measurement in the traverse direction were taken, the highest and lowest values were discarded and the average value was recorded. In this study, Ra values were measured between 0.55 and $2.74 \mathrm{~mm}$. The repeatability of the measurements was found to be in the range of $2-5 \%$, which was considered satisfactory for generating empirical models.

\subsubsection{Experimental design}

In this study, the experimental plan has four controllable variables namely, spindle speed, feed rate, depth of cut and step over. Thus, a minimum of 16 runs is required to develop a full second-order model. Meanwhile, plans with some highly desirable properties such as rotatability, orthogonal or uniform precision require more runs. Among various designs, the rotatable central composite design has the most popular promising outstanding benefits. In this study, a rotatable central composite (uniform precision) design with six central replicates was selected, with five different levels for each variable, as shown in Table 3. Variable ranges were determined on the basis of a cutting tool catalog. As presented in Table 4, the experimental plan was composed of a full 24 factorial with four central replicates (runs 1-20), augmented by eight axial runs with two central replicates (runs 21-30) to estimate second-order effects.

For the selection of the best model, the adjusted coefficient of multiple correlations. 

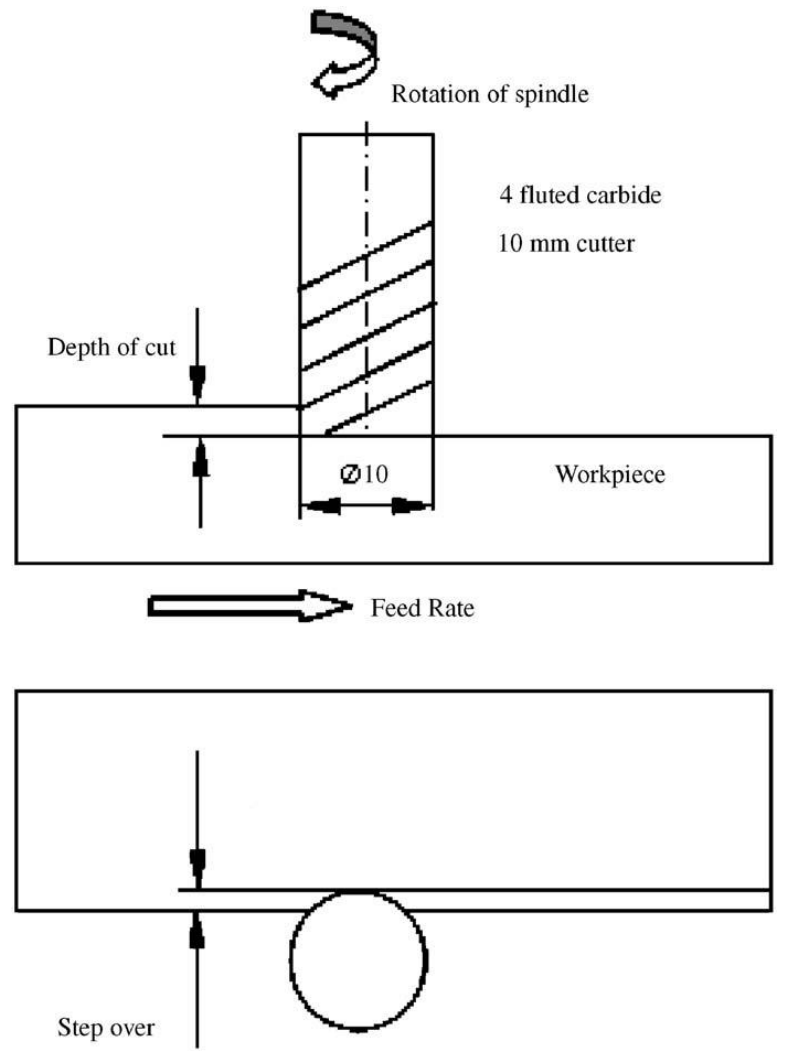

Fig.5.1.Schematic representation of workpiece and flat end mill

The machining conditions at which the experiments were conducted are listed in Table 5.1.

Table 5.1 Machining conditions

\begin{tabular}{|l|l|l|}
\hline 1 & Work piece & En-24 (SAE 4340) \\
\hline 2 & Chemical & C-0.39\%, Si-0.24\%, Mn-0.71\%,P- \\
\hline 3 & Work piece size & $60 \mathrm{mmX60mmX40mm}$ \\
\hline 4 & Surface & Portable Mitutoyo Surf Test 301 \\
\hline
\end{tabular}

\subsection{IDENTIFYING PROCESS PARAMETERS}

Optimal performance of any machining process is based on choosing the right combination of input parameters. End milling process is so stochastic in nature that the selection of optimal parameters is not possible by trial and error method. Research has been carried out to study the effect of several process parameters on $\mathrm{Ra}$ and . Based on some literature survey and preliminary investigations, the following four parameters are chosen as input parameters.
1. Spindle speed (rpm)
2. Feed Rate $(\mathrm{mm} / \mathrm{min})$
3. Depth of cut $(\mathrm{mm})$
4. Step over(mm)

\subsection{FINDING THE UPPER AND LOWER LIMITS OF THE CONTROL VARIABLES}

The upper and lower limits of the process variables are identified. The upper limit of a factor was coded +2 and lower limit as -2 . The selected process parameters with their limit values are given in the Table 5.2

Table 5.2 Control factors and their levels

\begin{tabular}{|l|l|l|l|l|l|l|l|}
\hline $\begin{array}{l}\text { S.n } \\
\text { o }\end{array}$ & $\begin{array}{l}\text { parame } \\
\text { ter }\end{array}$ & $\begin{array}{l}\text { Notati } \\
\text { on }\end{array}$ & -2 & -1 & 0 & 1 & 2 \\
\hline 1 & $\begin{array}{l}\text { Spindle } \\
\text { speed }\end{array}$ & $\mathrm{X} 1$ & $\begin{array}{l}400 \\
0\end{array}$ & $\begin{array}{l}550 \\
0\end{array}$ & $\begin{array}{l}700 \\
0\end{array}$ & $\begin{array}{l}850 \\
0\end{array}$ & $\begin{array}{l}100 \\
00\end{array}$ \\
\hline 2 & $\begin{array}{l}\text { Feed } \\
\text { Rate }\end{array}$ & $\mathrm{X} 2$ & 640 & $\begin{array}{l}132 \\
0\end{array}$ & $\begin{array}{l}224 \\
0\end{array}$ & $\begin{array}{l}340 \\
0\end{array}$ & $\begin{array}{l}480 \\
0\end{array}$ \\
\hline 3 & $\begin{array}{l}\text { Depth } \\
\text { of cut }\end{array}$ & $\mathrm{X} 3$ & 0.1 & 0.3 & 0.5 & 0.7 & 0.9 \\
\hline 4 & $\begin{array}{l}\text { Step } \\
\text { over }\end{array}$ & $\mathrm{X} 4$ & 1 & 2 & 3 & 4 & 5 \\
\hline
\end{tabular}

\subsection{DEVELOPING THE DESIGN MATRIX}

In this work Design Expert 7.1.4 was used to obtain the central composite second order rotatable design. The selected design matrix, is a three-level, four factor central composite rotatable factorial design (CCD) consisting of 30 sets of coded conditions. It comprises a half replication of 23 factorial design plus three center points and eight star points. CCD is a very efficient design for fitting the second-order model [18]. The machining time and the surface roughness (Ra) are considered as the output responses.

\subsection{CONDUCTING THE EXPERIMENTS AS PER THE DESIGN MATRIX AND RECORDING THE RESPONSES}

Experiments were conducted according to the design matrix that has been developed by Design Expert 8.0.1 and the corresponding surface roughness (Ra) and Machining time(MT) are tabulated in the Table 6.3.The MRR is calculated as the ratio of volume of material removed from work piece to the machining time. The $\mathrm{Ra}$ was measured in perpendicular to the cutting direction using Surtronic (surface roughness tester) at a $0.8 \mathrm{~mm}$ cut-off value. For each sample, three readings of surface roughness are taken and an average of three measurements taken at three different places is recorded as the final reading. 
Table 5.3 Central composite design with corresponding output values of $R_{a}$ and MT(Parent population $P_{t}$ )

\begin{tabular}{|c|c|c|c|c|c|c|}
\hline S.no. & $\begin{array}{c}\mathrm{X}_{l} \\
(\mathrm{~mm})\end{array}$ & $\begin{array}{c}\mathrm{X}_{l} \\
(\text { deg. })\end{array}$ & $\begin{array}{c}\mathrm{X}_{\mathrm{I}} \\
(\mathrm{mm} / \mathrm{rer})\end{array}$ & $\begin{array}{c}\mathrm{X} \\
(\mathrm{m} / \mathrm{min})\end{array}$ & $\begin{array}{c}\text { Roughness } \\
(\mu \mathrm{m})\end{array}$ & $\begin{array}{c}\text { IT } \\
(\mathrm{min})\end{array}$ \\
\hline 1 & 8500 & 1320 & 0.7 & 4 & 0.76 & 1.30 \\
\hline 2 & 5500 & 1320 & 0.3 & 4 & 0.86 & 1.30 \\
\hline 3 & 7000 & 2240 & 0.5 & 3 & 1.26 & 1.28 \\
\hline 4 & 5500 & 3400 & 0.7 & 4 & 2.57 & 0.72 \\
\hline 5 & 5500 & 1320 & 0.7 & 2 & 1.09 & 2.45 \\
\hline 6 & 7000 & 2240 & 0.5 & 3 & 1.20 & 1.28 \\
\hline 7 & 8500 & 1320 & 0.3 & 2 & 0.55 & 2.45 \\
\hline 8 & 8500 & 3400 & 0.7 & 2 & 0.68 & 1.53 \\
\hline 9 & 5500 & 3400 & 0.3 & 2 & 0.70 & 1.53 \\
\hline 10 & 8500 & 3400 & 0.3 & 4 & 1.04 & 0.72 \\
\hline 11 & 5500 & 3400 & 0.7 & 2 & 2.74 & 1.53 \\
\hline 12 & 5500 & 3400 & 0.3 & 4 & 1.13 & 0.72 \\
\hline 13 & 5500 & 1320 & 0.3 & 2 & 0.73 & 2.45 \\
\hline 14 & 7000 & 2240 & 0.5 & 3 & 1.30 & 1.28 \\
\hline 15 & 8500 & 3400 & 0.7 & 4 & 1.75 & 0.72 \\
\hline 16 & 8500 & 1320 & 0.3 & 4 & 0.66 & 1.30 \\
\hline 17 & 7000 & 2240 & 0.5 & 3 & 1.23 & 1.28 \\
\hline 18 & 8500 & 3400 & 0.3 & 2 & 0.57 & 1.53 \\
\hline 19 & 5500 & 1320 & 0.7 & 4 & 1.43 & 1.30 \\
\hline 20 & 8500 & 1320 & 0.7 & 2 & 0.83 & 2.45 \\
\hline 21 & 7000 & 2240 & 0.5 & 3 & 1.27 & 1.28 \\
\hline 22 & 10000 & 2240 & 0.5 & 3 & 0.91 & 1.28 \\
\hline 23 & 7000 & 4800 & 0.5 & 3 & 2.10 & 1.00 \\
\hline 24 & 7000 & 2240 & 0.5 & 1 & 0.87 & 3.68 \\
\hline 25 & 7000 & 2240 & 0.9 & 3 & 1.81 & 1.28 \\
\hline 26 & 7000 & 2240 & 0.1 & 3 & 0.74 & 1.28 \\
\hline 27 & 7000 & 2240 & 0.5 & 3 & 1.29 & 1.28 \\
\hline 28 & 4000 & 2240 & 0.5 & 3 & 2.08 & 1.28 \\
\hline 29 & 7000 & 2240 & 0.5 & 5 & 1.32 & 0.83 \\
\hline 30 & 7000 & 640 & 0.5 & 3 & 1.32 & 2.92 \\
\hline & & & & & & \\
\hline
\end{tabular}

\subsection{DEVELOPMENT OF MATHEMATICAL}

\section{MODELS USING DESIGN EXPERT 8.0.1}

In the present study, mathematical relationships between the control variables and the output responses were developed using the RSM. The need in developing the mathematical relationships is to relate the machining responses to the cutting parameters thereby facilitating the optimization of the machining process. Design Expert-8.0.1 statistical analysis software, was used to compute the regression coefficients of the proposed models. Because of the lower predictability of the first-order models for the present problem, the second-order models were postulated. The analysis of variance (ANOVA) was used to check the adequacy of the developed models.

\subsection{FORMULATION OF OPTIMIZATION PROBLEM}

In the process of optimization, the aim is to minimam the MT and minimize the Ra, which forms the multi-objective optimization problem. Equations (5.1) and (5.2) represent the $\mathrm{Ra}$ and the MT respectively. The complexities of the models were reduced by applying the back elimination procedure. The final equations, after eliminating the insignificant terms, are as follows:

$\mathrm{SR}=+2.26873-\left(0.00069186^{*} \mathrm{~A}\right)-$

$(0.000317182 * \mathrm{~B})+(0.040858 * \mathrm{C})+(0.72572 * \mathrm{D})+(0.000000007$ $24712 * \mathrm{~A} * \mathrm{~B})-(0.000114881 * \mathrm{~A} * \mathrm{C})-$ $(0.0000531375 * \mathrm{~A} * \mathrm{D})+(0.000882196 * \mathrm{~B} * \mathrm{C})+(0.00000263901$ $* \mathrm{~B} * \mathrm{D})+(0.27752 * \mathrm{C} * \mathrm{D})+(0.0000000581981 * \mathrm{~A} * \mathrm{~A})+(0.000000$ $00286653 * \mathrm{~B} * \mathrm{~B})-(0.39175 * \mathrm{C} * \mathrm{C})-(0.06067 * \mathrm{D} * \mathrm{D})$;

$\mathrm{MT}=+5.05321+(0.000488891 * \mathrm{~A})-$

$(0.00137808 * \mathrm{~B})+(0.83823 * \mathrm{C})-(1.76017 * \mathrm{D})-$ $(0.0000000359534 * \mathrm{~A} * \mathrm{~B})+(0.0000582352 * \mathrm{~A} * \mathrm{C})-$ $(0.0000213060 * \mathrm{~A} * \mathrm{D})+(0.0000197961 * \mathrm{~B} * \mathrm{C})+(0.0000605759$ $* \mathrm{~B} * \mathrm{D})-(0.019818 * \mathrm{C} * \mathrm{D})-$ $(0.0000000284298 * \mathrm{~A} * \mathrm{~A})+(0.000000216738 * \mathrm{~B} * \mathrm{~B})-$ $(1.16075 * \mathrm{C} * \mathrm{C})+(0.19732 * \mathrm{D} * \mathrm{D})$;

In the above equations, $\mathrm{A}, \mathrm{B}, \mathrm{C}$ and $\mathrm{D}$ represent the logarithmic transformations of depth of cut, horizontal inclination angle, feed and cutting speed respectively and are given below:

$$
\begin{aligned}
& A_{4}=\frac{\ln \left(X_{0}\right)-\ln (0.4)}{\ln (0.6)-\ln (0.4)} \\
& A_{6}=\frac{\ln \left(X_{1}\right)-\ln (30)}{\ln (50)-\ln (30)} \\
& A_{3}=\frac{\ln \left(X_{1}\right)-\ln (0.96)}{\ln (1.36)-\ln (0.96)} . \\
& A_{4}=\frac{\ln \left(X_{3}\right)-\ln (200)}{\ln (250)-\ln (200)}
\end{aligned}
$$

The above relations were obtained from the following transformation equation:

$$
A=\frac{\ln \left(X_{n}\right)-\ln \left(X_{n 0}\right)}{\ln \left(X_{n 1}\right)-\ln \left(X_{n 0}\right)}
$$

where A is the coded value of any factor corresponding to its natural value $\mathrm{Xn} ; \mathrm{Xn} 1$ is the natural value of the factor at the + 1 level, and $\mathrm{Xn} 0$ is the natural value of the factor 
corresponding to the base level or zero level. The objective functions were optimized subject to the feasible bounds of the control variables. Table 5.4 exhibits the feasible bounds for each variable.

\begin{tabular}{|c|c|c|}
\hline Variable & lower limit & upper limit \\
\hline $\begin{array}{l}\text { Spindle speed(A) in } \\
\text { rpm }\end{array}$ & 4000 & 10000 \\
\hline $\begin{array}{l}\text { Feed rate }(\mathrm{B}) \text { in } \\
\mathrm{mm} / \mathrm{min}\end{array}$ & 640 & 4800 \\
\hline $\begin{array}{l}\text { Depth of } \operatorname{cut}(\mathrm{C}) \text { in } \\
\mathrm{mm}\end{array}$ & 0.1 & 0.9 \\
\hline Step over(D) in mm & 1 & 5 \\
\hline
\end{tabular}

\subsection{SIGNIFICANCE OF REGRESSION COEFFICIENTS}

In statistics, the coefficient of determination $\mathrm{R} 2$ (R-Sq) is the proportion of variability in a data set that is accounted for by a statistical model. In this definition, the term variability" is defined as the sum of squares. R2 is a statistic that will give some information about the goodness of fit of a model. In regression, the R2 coefficient of determination is a statistical measure of how well the regression line approximates the real data points. The value of R2 in quadratic model for MT is 0.9510 which means that the regression model provides an excellent explanation of the relationship between the independent variables (factors) and the response (MT). The value of R2 in quadratic model for the surface roughness is 0.8812 which means that the regression model provides an excellent explanation of the relationship between the independent variables (factors) and the response (Ra) which indicates that the model is considered statistically significant.

\subsection{ANALYSIS OF PROCESS PARAMETERS ON OUTPUTS (Ra AND MT)}

Table 6.5 shows the ANOVA for the Ra. The P-value for the model is lower than 0.05 (i.e. at $95 \%$ confidence level) indicates that the model is considered to be statistically significant [22]. Similar analysis was carried out for the MT and is given in Table 5.6.
Table 5.5 Analysis of variance for $\mathrm{R}_{\mathrm{a}}: 1$

\begin{tabular}{|c|c|c|c|c|c|}
\hline Source & $\begin{array}{l}\text { Sum of } \\
\text { Squares }\end{array}$ & $\mathrm{df}$ & $\begin{array}{l}\text { Mean } \\
\text { Square }\end{array}$ & $\begin{array}{c}\mathrm{F} \\
\text { Value }\end{array}$ & $\begin{array}{l}\text { p-value } \\
\text { Prob }>F\end{array}$ \\
\hline Model & 8.234 & 14 & 0.59 & 7.95 & 0.0001 significant \\
\hline$A \cdot A$ & 2.06 & 1 & 2.06 & 27.86 & $<0.0001$ \\
\hline B.B & 1.49 & 1 & 1.49 & 20.13 & 0.0004 \\
\hline $\mathrm{C}-\mathrm{C}$ & 3.08 & 1 & 3.08 & 41.60 & $<0.0001$ \\
\hline D.D & 0.54 & 1 & 0.54 & 7.24 & 0.0168 \\
\hline$A B$ & 0.20 & 1 & 0.20 & 2.66 & 0.1235 \\
\hline $\mathrm{AC}$ & 0.64 & 1 & 0.64 & 8.70 & 0.0099 \\
\hline $\mathrm{AD}$ & 0.045 & 1 & 0.045 & 0.61 & 0.4468 \\
\hline $\mathrm{BC}$ & 0.58 & 1 & 0.58 & 7.78 & 0.0138 \\
\hline $\mathrm{BD}$ & 0.11 & 1 & 0.11 & 1.44 & 0.2484 \\
\hline$C D$ & $5.625 \mathrm{E}-005$ & 1 & $5.625 \mathrm{E}-005$ & 7.603 .000 & 0.9784 \\
\hline$A^{2}$ & $5.382 \mathrm{E}-003$ & 1 & $5.382 \mathrm{E}-003$ & 0.073 & 0.7911 \\
\hline$B^{2}$ & 0.027 & 1 & 0.027 & 0.37 & 0.5532 \\
\hline$c^{2}$ & 0.046 & 1 & 0.046 & 0.62 & 0.4423 \\
\hline$D^{2}$ & 0.20 & 1 & 0.20 & 2.74 & 0.1185 \\
\hline Residual & 1.11 & 15 & 0.074 & & \\
\hline Lack of Fit & 1.10 & 10 & 0.11 & 77.84 & $<0.0001$ not significant \\
\hline Pure Error & $7.083 \mathrm{E}-003$ & 5 & $1.417 \mathrm{E}-003$ & & \\
\hline Corr Total & 9.34 & 29 & & & \\
\hline
\end{tabular}

\section{Response $1 \quad \mathbf{R}_{\mathrm{a}}$ ANOVA for Response Surface Quadratic Model Analysis of variance table [Partial sum of squares - Type III]}

The Model F-value of 7.95 implies the model is significant. There is onlya $0.01 \%$ chance that a "Model F-Value" this large could occur due to noise. Values of "Prob > F" less than 0.0500 indicate model terms are significant. In this case A, B, C, D, $\mathrm{AC}, \mathrm{BC}$ are significant model terms. Values greater than 0.1000 indicate the model terms are not significant. If there are many insignificant model terms (not counting those required to supporthierarchy), model reduction may improve your model.The "Lack of Fit F-value" of 77.84 implies the Lack of Fit is significant. There is only a0.01\% chance that a "Lack of Fit F-value" this large could occur due to noise.Significant lack of fit is bad -- we want the model to fit. 

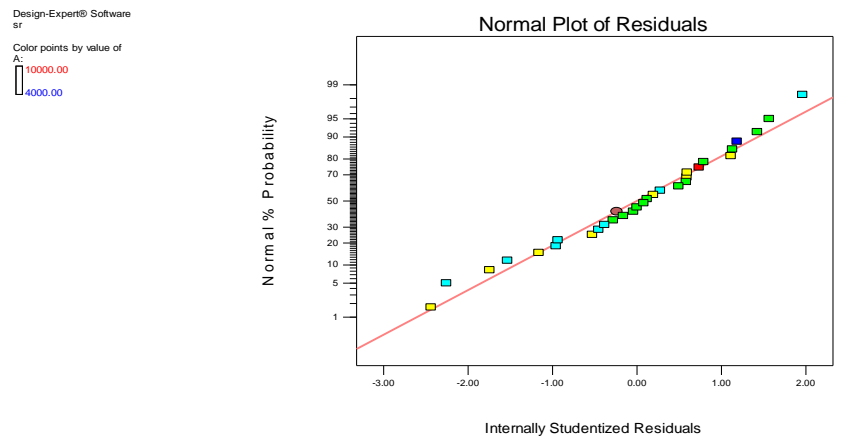

Fig 5.2 normal probability plot of the residuals for surface roughness
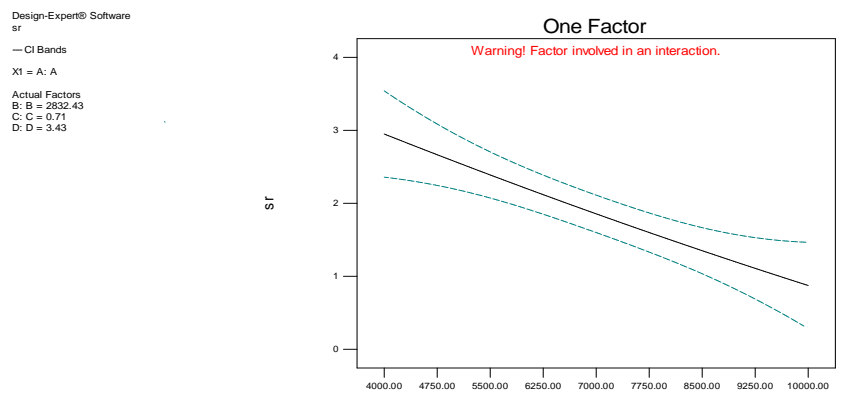

A: A

Fig 5.3 effect of spindle speed on surface roughness
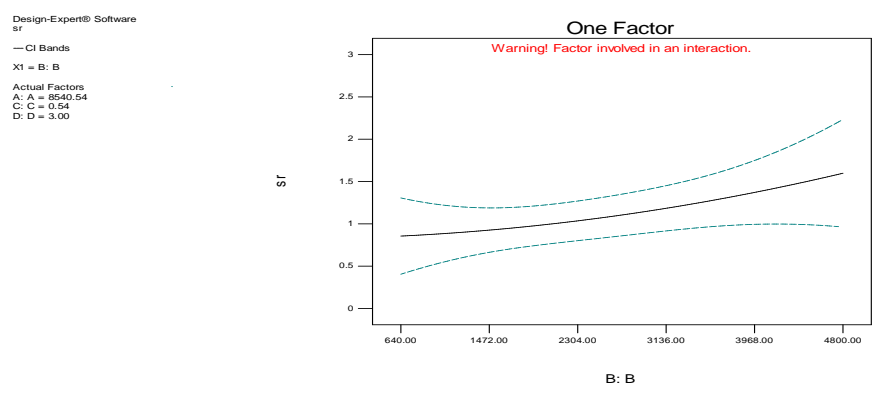

Fig 5.4 effcect of feed rate on surface roughness
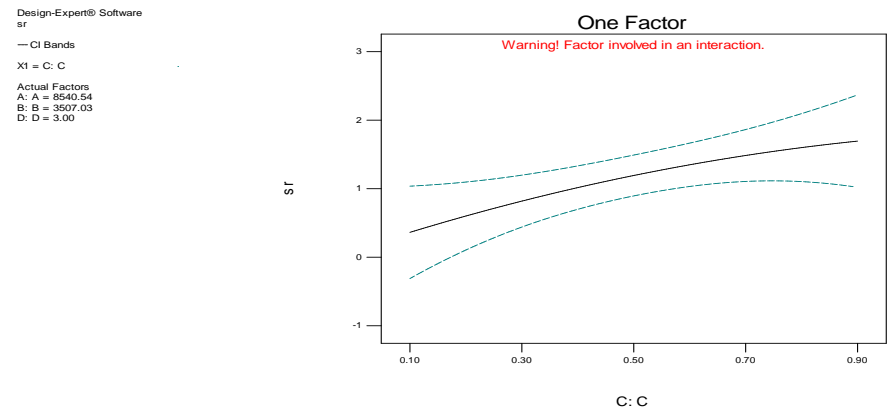

Fig 5.5 effect of depth of cut on surface roughness
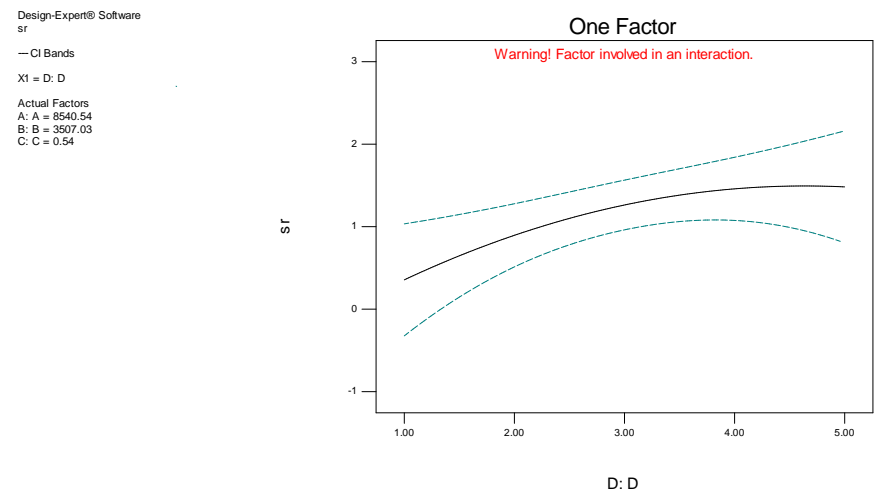

Fig 5.6 effect of step over on surface roughness

Table. 5.7. varience for MT:Response2mtANOVAfor Response Surface Quadratic ModelAnalysis of variance table [Partial sum of squares - Type III]

\begin{tabular}{|c|c|c|c|c|c|}
\hline Source & $\begin{array}{l}\text { Sum of } \\
\text { Squares }\end{array}$ & df & $\begin{array}{c}\text { Mean } \\
\text { Square }\end{array}$ & $\begin{array}{c}\text { F } \\
\text { Value }\end{array}$ & $\begin{array}{l}\text { p-value } \\
\text { Prob }>F\end{array}$ \\
\hline Model & 13.46 & 14 & 0.96 & 20.79 & 60.0001 significant \\
\hline A-A & 0.000 & 1 & 0.000 & 0.000 & 1.0000 \\
\hline B-B & 2.62 & 1 & 2.62 & 56.62 & $<0.0001$ \\
\hline $\mathrm{C}-\mathrm{C}$ & 0.000 & 1 & 0.000 & 0.00 & 1.0000 \\
\hline D-D & 5.62 & 1 & 5.62 & 121.55 & $<0.0001$ \\
\hline$A B$ & 0.000 & 1 & 0.000 & 0.000 & 1.0000 \\
\hline $\mathrm{AC}$ & 0.000 & 1 & 0.000 & 0.000 & 1.0000 \\
\hline $\mathrm{AD}$ & 0.000 & 1 & 0.000 & 0.000 & 1.0000 \\
\hline $\mathrm{BC}$ & 0.000 & 1 & 0.000 & 0.000 & 1.0000 \\
\hline $\mathrm{BD}$ & 0.14 & 1 & 0.14 & 3.01 & 1.1031 \\
\hline $\mathrm{CD}$ & 0.000 & 1 & 0.000 & 0.000 & 1.0000 \\
\hline $\mathrm{A}^{2}$ & 0.034 & 1 & 0.034 & 0.73 & 0.4051 \\
\hline $\mathrm{B}^{2}$ & 0.73 & 1 & 0.73 & 15.78 & 0.0012 \\
\hline $\mathrm{C}^{2}$ & 0.034 & 1 & 0.034 & 0.73 & 0.4051 \\
\hline $\mathrm{D}^{2}$ & 1.19 & 1 & 1.19 & 25.79 & 0.0001 \\
\hline Residual & 0.69 & 15 & 0.046 & & \\
\hline Lack of Fit & 0.69 & 10 & 0.069 & 11.98 & 0.075 not significant \\
\hline Pure Error & 0.000 & 5 & 0.000 & & \\
\hline Cor Total & 14.16 & 29 & & & \\
\hline
\end{tabular}

The Model F-value of 20.79 implies the model is significant.There is onlya $0.01 \%$ chance that a "Model FValue" this large could occur due to noise. Values of "Prob > F" less than 0.0500 indicate model terms are significant.In this case B, D, B2, D2 are significant model terms. Values greater than 0.1000 indicate the model terms are not significant. If there are many insignificant model terms (not counting those required to support hierarchy), model reduction may improve your model. 


\begin{tabular}{|c|c|c|c|c|}
\hline Std. Dev. & 0.22 & R-Squared & 0.9510 & $\begin{array}{l}\text { Design-Expente Sotivar } \\
\mathrm{mt}\end{array}$ \\
\hline Mean & 1.51 & Adj R-Squared & 0.9052 & $\begin{array}{l}-\mathrm{Cl} \text { Bands } \\
\mathrm{X} 1=\mathrm{B}: \mathrm{B}\end{array}$ \\
\hline C.V. $\%$ & 14.27 & Pred R-Squared & 0.7681 & $\begin{array}{l}\text { Actual Factors } \\
A: A=700000\end{array}$ \\
\hline PRESS & 3.28 & Adeq Precision & 17.385 & $\begin{array}{l}\mathrm{C}: \mathrm{C}=0.34 \\
\mathrm{D}: \mathrm{D}=1.43\end{array}$ \\
\hline
\end{tabular}

The "Pred R-Squared" of 0.7681 is in reasonable agreement with the "Adj R-Squared" of 0.9052."Adeq Precision" measures the signal to noise ratio. A ratio greater than 4 is desirable. Your ratio of 17.385 indicates an adequate signal. This model can be used to navigate the design space.

$\begin{array}{lrlc}\text { Std. Dev. } & 0.22 & \text { R-Squared } & 0.9510 \\ \text { Mean } & 1.51 & \text { Adj R-Squared } & 0.9052 \\ \text { C.V. \% } & 14.27 & \text { Pred R-Squared } & 0.7681 \\ \text { PRESS } & 3.28 & \text { Adeq Precision } & 17.385\end{array}$

The "Pred R-Squared" of 0.7681 is in reasonable agreement with the "Adj R-Squared" of 0.9052."Adeq Precision" measures the signal to noise ratio. A ratio greater than 4 is desirable. Your ratio of 17.385 indicates an adequate signal. This model can be used to navigate the design space.

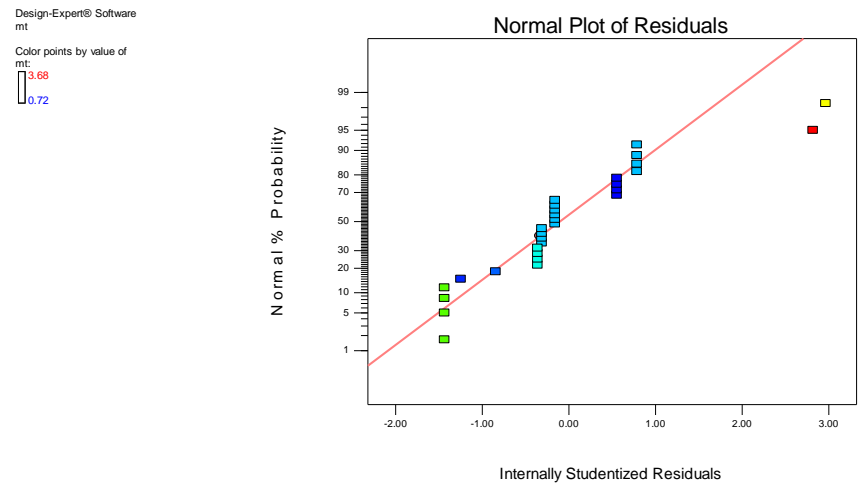

Fig5.7 Normal probability plot of the residual for machining time

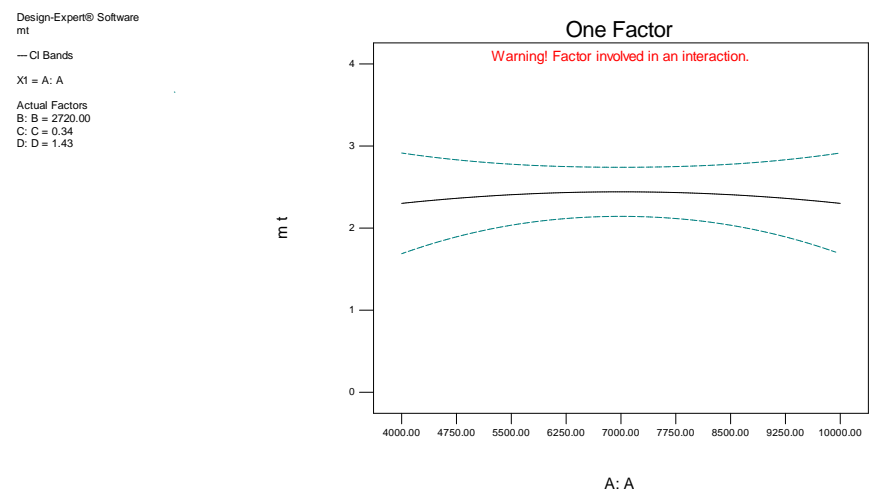

Fig 5.8 effect of spindle speed on machining time

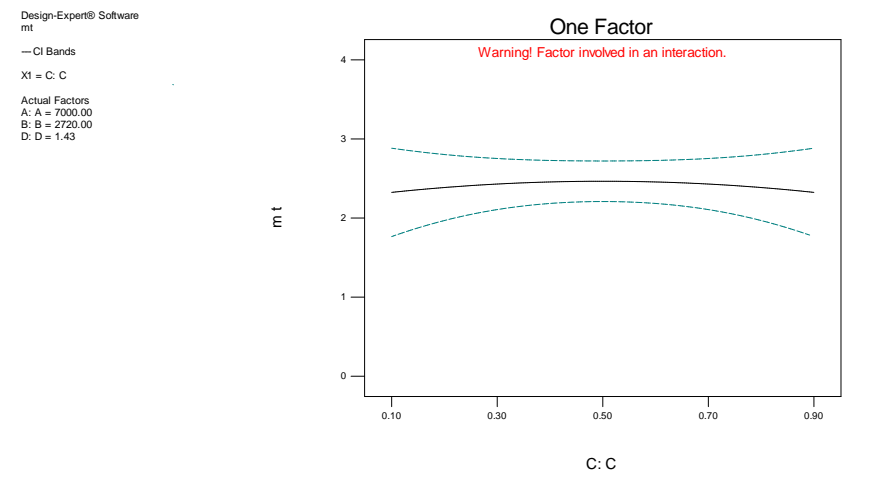

Fig 5.10 effect of depth of cut on aching time
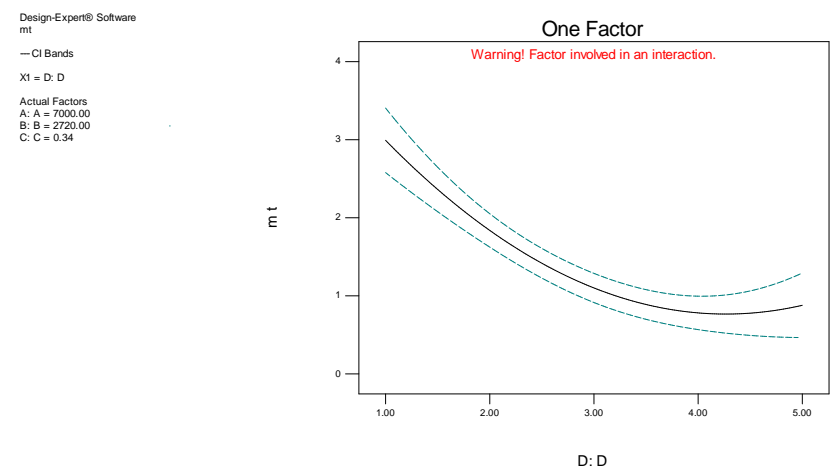

Fig 5.11 effect of step over on machining time

The following equations were obtained for the Ra and MT in terms of the coded factors:

$\mathrm{R}_{\mathrm{a}}=-0.83990+1.18148 \mathrm{E}-004 * \mathrm{~A}-9.81121 \mathrm{E}-005 * \mathrm{~B}+5.18185$ * C+0.21532* D-7.09837E

$-008 * \mathrm{~A} * \mathrm{~B}-6.68750 \mathrm{E}-00 * \mathrm{~A} * \mathrm{C}+3.54167 \mathrm{E}-005 * \mathrm{~A} *$ $\mathrm{D}+9.09771 \mathrm{E}-004 * \mathrm{~B} * \mathrm{C}$ 


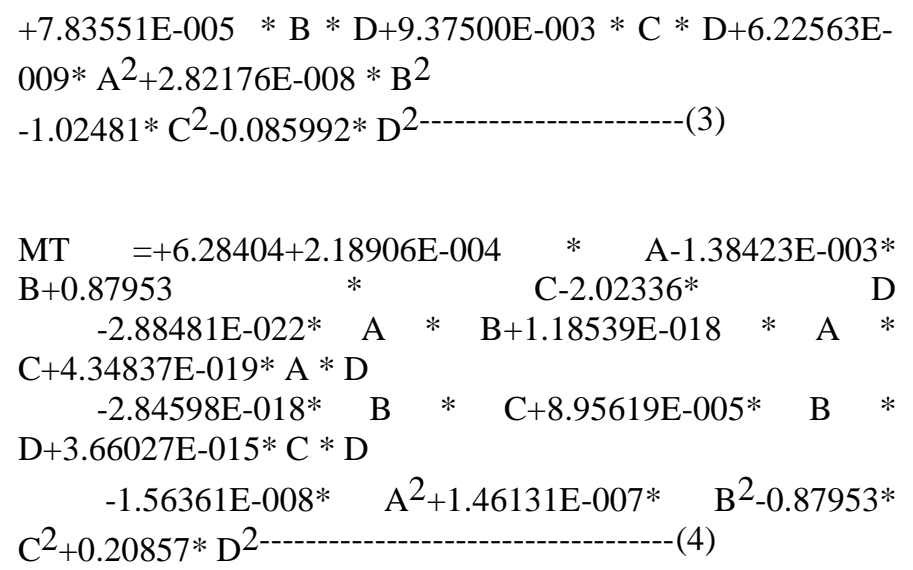

\subsection{IMPLEMENTATION}

Tables 5.7 to 5.9 display the implementation of NSGA for the present problem. Sample calculations are shown for one iteration of the algorithm. The bit lengths chosen for $\mathrm{X} 1, \mathrm{X} 2$, $\mathrm{X} 3$ and $\mathrm{X} 4$ are 4, 5, 4, and 3 respectively. It refers to the number of binary digits chosen for an individual control variable. As a first step, in the algorithm, an initial population of 27 chromosomes was generated randomly.

Table 5.7. Lower and upper bounds and bit length for all variables

\begin{tabular}{|c|c|c|c|c|}
\hline $\begin{array}{c}\text { Sr } \\
\text { N } \\
\mathbf{o}\end{array}$ & $\begin{array}{c}\text { Input } \\
\text { paramet } \\
\text { er }\end{array}$ & $\begin{array}{c}\text { Uppe } \\
\mathbf{r} \\
\text { limit }\end{array}$ & $\begin{array}{c}\text { Lowe } \\
\mathbf{r} \\
\text { limit }\end{array}$ & $\begin{array}{c}\text { Bit } \\
\text { lengt } \\
\mathbf{h}\end{array}$ \\
\hline 1 & Spindle speed & 4000 & 10000 & 4 \\
\hline 2 & Feed rate & 640 & 4800 & 5 \\
\hline 3 & Depth of cut & 0.1 & 0.9 & 4 \\
\hline 4 & Step over & 1 & 5 & 3 \\
\hline
\end{tabular}

\begin{tabular}{|c|c|c|c|c|c|c|c|c|}
\hline S.NO & CHROMOSOME & $\mathrm{X} 1$ & $\mathrm{X} 2$ & $\mathrm{X} 3$ & $\mathrm{X} 4$ & $\begin{array}{c}\text { Ra } \\
(\mu \mathrm{m})\end{array}$ & $\begin{array}{c}\text { MT } \\
(\mathrm{min})\end{array}$ & RANK \\
\hline 1 & 0000110001010000 & 4000 & 3860.64 & 0.63 & 1.00 & 1.7265 & 2.7444 & 7 \\
\hline 2 & 1010100000110011 & 8000 & 2787.10 & 0.42 & 2.71 & 1.0580 & 1.2042 & 4 \\
\hline 3 & 0001110001000111 & 9400 & 3860.64 & 0.53 & 5.00 & 2.4706 & 1.0280 & 4 \\
\hline 4 & 0011000000100011 & 5200 & 640.00 & 0.31 & 2.71 & 1.0419 & 2.6272 & 5 \\
\hline 5 & 1011001010111110 & 8400 & 1310.97 & 0.47 & 4.43 & 0.8953 & 1.2960 & 4 \\
\hline 6 & 1110110001001110 & 9600 & 3860.64 & 0.58 & 1.00 & 1.6309 & 2.6233 & 6 \\
\hline 7 & 1100001100011100 & 8800 & 1445.16 & 0.26 & 3.28 & 0.8228 & 1.4426 & 4 \\
\hline 8 & 1111110110000010 & 10000 & 4263.22 & 0.10 & 2.14 & 0.6617 & 0.9988 & 1 \\
\hline 9 & 1100000011010011 & 8800 & 714.19 & 0.63 & 2.71 & 0.8708 & 2.7077 & 4 \\
\hline 10 & 1110010010101011 & 9600 & 1847.74 & 0.37 & 2.71 & 1.2943 & 1.4622 & 5 \\
\hline 11 & 0110100011010110 & 6400 & 3994.84 & 0.63 & 4.43 & 2.1548 & 0.8915 & 2 \\
\hline 12 & 1001010000010101 & 7600 & 1713.55 & 0.21 & 3.85 & 0.6385 & 1.0667 & 1 \\
\hline 13 & 0100111101010101 & 5600 & 4665.81 & 0.63 & 3.85 & 2.5190 & 1.3084 & 5 \\
\hline 14 & 1001110100011010 & 7600 & 4129.03 & 0.26 & 2.14 & 0.7162 & 0.9585 & 2 \\
\hline 15 & 1101010000011100 & 9200 & 1713.55 & 0.26 & 3.28 & 0.8867 & 1.1706 & 3 \\
\hline 16 & 1010100101000000 & 8000 & 3055.48 & 0.53 & 1.00 & 0.9415 & 2.9172 & 5 \\
\hline 17 & 1010000110101111 & 8000 & 1042.58 & 0.37 & 5.00 & 0.6667 & 1.5341 & 2 \\
\hline 18 & 1100011010010001 & 8800 & 2384.52 & 0.21 & 1.57 & 0.6771 & 2.2369 & 3 \\
\hline 19 & 0110100101100110 & 6400 & 3055.48 & 0.74 & 5.00 & 2.1689 & 0.7350 & 1 \\
\hline 20 & 0011100001000010 & 5200 & 2787.10 & 0.53 & 3.14 & 1.6840 & 1.0242 & 3 \\
\hline 21 & 1011110001110011 & 8400 & 3860.64 & 0.79 & 2.71 & 2.2661 & 1.0680 & 4 \\
\hline 22 & 0000101011000111 & 4000 & 3458.06 & 0.53 & 5.00 & 2.5852 & 0.8617 & 3 \\
\hline 23 & 0100111111000110 & 5600 & 4800.00 & 0.53 & 4.43 & 2.1865 & 1.4411 & 6 \\
\hline 24 & 0001111110001111 & 4400 & 4800.00 & 0.15 & 5.00 & 0.8189 & 1.5281 & 3 \\
\hline 25 & 0011101001011100 & 5200 & 3323.87 & 0.69 & 3.28 & 2.2784 & 0.9010 & 3 \\
\hline 26 & 0100100110010111 & 5600 & 3188.68 & 0.21 & 5.00 & 0.7709 & 0.7541 & 1 \\
\hline 27 & 0101110011100001 & 6000 & 3994.84 & 0.74 & 1.57 & 1.9069 & 2.2358 & 6 \\
\hline 28 & 1111001100011000 & 10000 & 1445.16 & 0.26 & 1.00 & 1.0488 & 3.6455 & 6 \\
\hline 29 & 1111100011001010 & 10000 & 2921.29 & 0.58 & 2.14 & 1.6989 & 1.3747 & 5 \\
\hline 30 & 1010111001100110 & 8000 & 4397.42 & 0.74 & 4.43 & 2.4828 & 0.83998 & 2
\end{tabular}

Then the population was classified into different levels of nondomination sets. In this approach, each solution has to be compared with every other solution in the population. For example, the objective function values of the first chromosome for the $\mathrm{Ra}$ and the MRR are 1.6261 and 2.3288 respectively. They were then compared with the corresponding objective function values of the second chromosome and subsequently with the values of other chromosomes in the population. The values of objective 1 and objective 2 are greater for the first chromosome when compared to the second chromosome. Therefore, it can be said that the first chromosome is non-dominating with respect to second one. The comparison was continued for all other chromosomes in the population and as the first chromosome is still non-dominant, it was ranked as 1 . Similarly, each non-dominant chromosome obtained in first sorting was given as rank 1. Then disregarding these 
chromosomes temporarily again sorting was done for the remaining chromosomes. All non-dominant chromosomes obtained in second sorting were given as rank 2. This procedure was repeated till all chromosomes in the population were sorted and ranked. Eventually, the members of the population were classified into four distinct non-dominated sets as shown in Table 5.8.

To preserve the diversity among the chromosomes of the populations, sharing function method as explained in section 3 was used. In this method, initially, the Euclidean distances between the chromosomes of first front were computed. The distance values of $0.0000,0.1149$, $0.2970, \quad 0.6089,0.9286,0.3383,0.0042,1.0879,0.7523$ and 0.3288 were obtained for the first chromosome with reference to the chromosomes $1,3,4,5,9,13,19,21,22$ and 23 respectively. The sharing function values were subsequently computed using equation (7) by choosing oshare value as 0.35 . Then the niche count for the first front was computed based on equation (8). Similar procedure was applied to calculate the niche count values for the other fronts. The niche count values obtained for each chromosome are listed in Table 6.9.

A dummy fitness (Fi) equal to the population size (27) was assigned to all chromosomes of the first front. Then the shared fitness (F') value of each chromosome in the first front was obtained using equation (5). This process of degrading the fitness of a solution which is crowded by many solutions helps to emphasize the solutions residing in less crowded regions. Similarly, the shared fitness values for other chromosomes were computed. Dummy fitness for chromosomes in the second front is obtained as 5.8816 by subtracting a small value of 0.12 from the minimum shared fitness value of the first front. This makes sure that no solution in the first front has shared fitness worse than the assigned fitness of any solution in the second front. This procedure was continued until all the solutions are assigned a shared fitness value. Table 6.9 illustrates the above procedure.

Roulette-wheel selection operator was used to pick-up the good solutions from the population. This operator assigns number of copies in the mating pool proportional to the shared fitness. In this process, initially, the probability of selecting each chromosome (pi) was calculated by dividing the individual shared fitness value with the sum of fitness values of all chromosomes in the population. Thereafter, the cumulative probability (Pi) of each chromosome was calculated by adding the individual probabilities from the top of the Table. In order to choose $\mathrm{n}$ strings, $\mathrm{n}$ random numbers between zero and one were created at random. Thus, a string that represents the chosen random number in the cumulative probability range (calculated from the fitness values) for the chromosome was copied to the mating pool. For example, random number $(0.884)$ was created for the first chromosome; the twenty third chromosome got a copy in the mating pool, because that string occupies the interval $(0.8716,0.9524)$ as shown in the Table 6.9. Chromosomes with a higher fitness value represent a larger range in the cumulative probability values and therefore they have greater probability of being copied into the mating pool. On the other hand, a chromosome with a smaller fitness value represents a smaller range in cumulative probability value and has a smaller probability of being copied into the mating pool.

Table 5.9 Selection of chromosomes

\begin{tabular}{|c|c|c|c|c|c|}
\hline S.NO & $\begin{array}{l}\text { Shared Fitness } \\
\text { (F) }\end{array}$ & $\begin{array}{c}\text { Probability } \\
\text { (P) }\end{array}$ & $\begin{array}{c}\text { Cumulative } \\
\text { probability of } \\
\text { selection }\end{array}$ & Random Number & $\begin{array}{c}\text { Selected } \\
\text { Chromosome } \\
\text { Number }\end{array}$ \\
\hline 1 & 5.0000 & 0.0245 & 0.0245 & 0.337 & 12 \\
\hline 2 & 4.2661 & 0.0209 & 0.0454 & 0.770 & 24 \\
\hline 3 & 7.0395 & 0.0344 & 0.0798 & 0.724 & 22 \\
\hline 4 & 4.9659 & 0.0242 & 0.1040 & 0.671 & 20 \\
\hline 5 & 4.9980 & 0.0244 & 0.1248 & 0.434 & 14 \\
\hline 6 & 3.5100 & 0.0172 & 0.1456 & 0.555 & 17 \\
\hline 7 & 5.1305 & 0.0251 & 0.1707 & 0.073 & 03 \\
\hline 8 & 7.1655 & 0.0350 & 0.2057 & 0.697 & 21 \\
\hline 9 & 6.9557 & 0.0340 & 0.2397 & 0.041 & 02 \\
\hline 10 & 4.6889 & 0.0229 & 0.2626 & 0.945 & 30 \\
\hline 11 & 11.8946 & 0.0582 & 0.3208 & 0.747 & 22 \\
\hline 12 & 9.7752 & 0.0478 & 0.3686 & 0.186 & 08 \\
\hline 13 & 7.0675 & 0.0346 & 0.4032 & 0.297 & 11 \\
\hline 14 & 11.4207 & 0.0559 & 0.4591 & 0.836 & 26 \\
\hline 15 & 5.6944 & 0.0278 & 0.4869 & 0.228 & 09 \\
\hline 16 & 4.9898 & 0.0244 & 0.5113 & 0.252 & 10 \\
\hline 17 & 12.0592 & 0.0589 & 0.5702 & 0.816 & 25 \\
\hline 18 & 7.3083 & 0.0357 & 0.6059 & 0.769 & 24 \\
\hline 19 & 11.5052 & 0.0563 & 0.6622 & 0.774 & 22 \\
\hline 20 & 5.3953 & 0.0264 & 0.6886 & 0.833 & 26 \\
\hline 21 & 5.5079 & 0.0269 & 0.7155 & 0.162 & 07 \\
\hline 22 & 7.2579 & 0.0355 & 0.7510 & 0.735 & 22 \\
\hline 23 & 3.4125 & 0.0166 & 0.7676 & 0.906 & 28 \\
\hline 24 & 5.7850 & 0.0283 & 0.7959 & 0.849 & 26 \\
\hline 25 & 6.1003 & 0.0298 & 0.8257 & 0.533 & 17 \\
\hline 26 & 10.5917 & 0.0518 & 0.8775 & 0.260 & 10 \\
\hline 27 & 3.1609 & 0.0155 & 0.8930 & 0.989 & 30 \\
\hline 28 & 3.3521 & 0.0164 & 0.9094 & 0.766 & 23 \\
\hline 29 & 4.3162 & 0.0211 & 0.9305 & 0.636 & 19 \\
\hline 30 & 14.0900 & 0.0689 & 1.0000 & 0.647 & 19 \\
\hline
\end{tabular}

The chromosomes selected in the mating pool were used in the crossover operation. In this work, two-point crossover was adopted, in which, the portions of the strings between the randomly selected crossover sites were swapped to create the new intermediate population as shown in Table 6.10. However, with the random sites, the offspring produced may or may not have a combination of good substrings from parent strings, depending on whether or not the crossing sites fall in the appropriate locations. If good strings are not created by crossover, they will not survive too long, because reproduction will select against those chromosomes in subsequent generations. In order to preserve some of the good chromosomes that are already present in the mating pool, not all chromosomes in the mating pool are used in crossover. When a crossover probability of $\mathrm{pc}$ is used, the expected number of strings that will be subjected to crossover 
is only $100 \mathrm{pc}$ percent and the remaining percent of the population remains as they are in the current population. In this work, pc was chosen as 0.85 and the calculations are shown in Table 5.10.

\begin{tabular}{|c|c|c|c|c|c|c|}
\hline S.NO & $\begin{array}{c}\text { Selected } \\
\text { Chromosome } \\
\text { Number }\end{array}$ & Crossover & $\begin{array}{c}\text { Crossover } \\
\text { sites }\end{array}$ & Offspring & $\begin{array}{c}\text { Mutation } \\
\text { site }\end{array}$ & $\begin{array}{c}\text { Mutated } \\
\text { chromosome }\end{array}$ \\
\hline 1 & 12 & YES & 12,11 & 1001010000000101 & $\ldots$ & 1001010000000101 \\
\hline 2 & 24 & YES & 12,11 & 0001111110011111 & $\ldots$ & 0001111110011111 \\
\hline 3 & 22 & No & $\ldots$ & 0000101011000111 & $\ldots$ & 0000101011000111 \\
\hline 4 & 20 & No & $\ldots$ & 0011100001000010 & 5,11 & 0011100001100010 \\
\hline 5 & 14 & YES & 4,10 & 1000000110011010 & $\ldots$ & 1000000110011010 \\
\hline 6 & 17 & YES & 4,10 & 1011110100101111 & $\ldots$ & 1011110100101111 \\
\hline 7 & 03 & No & $\ldots$ & 0001110001000111 & $\ldots$ & 0001110001000111 \\
\hline 8 & 21 & YES & 7,11 & 1011100000110011 & 8,16 & 1011100100110011 \\
\hline 9 & 02 & YES & 7,11 & 1010100001110011 & $\ldots$ & 1010100001110011 \\
\hline 10 & 30 & YES & 14,11 & 1010111001000110 & 9 & 1010111001000110 \\
\hline 11 & 22 & YES & 14,11 & 0000101011100111 & $\ldots$ & 0000101011100111 \\
\hline 12 & 08 & YES & 5,6 & 1111100110000010 & $\ldots$ & 1111100110000010 \\
\hline 13 & 11 & YES & 5,6 & 0110110011010110 & 10 & 0110110011010110 \\
\hline 14 & 26 & YES & 2,4 & 0100100110010111 & $\ldots$ & 0100100110010111 \\
\hline 15 & 09 & YES & 2,4 & 1100000011010011 & 2,11 & 1100000011110011 \\
\hline 16 & 10 & No & $\ldots$ & 1110010010101011 & $\ldots$ & 1110010010101011 \\
\hline 17 & 25 & YES & 8,11 & 0011101010011100 & $\ldots$ & 0011101010011100 \\
\hline 18 & 24 & YES & 8,11 & 0001111101001111 & $\ldots$ & 0001111101001111 \\
\hline 19 & 22 & No & $\ldots$ & 0000101011000111 & $\ldots$ & 0000101011000111 \\
\hline 20 & 26 & No & $\ldots$ & 0100100110010111 & $\ldots$ & 0100100110010111 \\
\hline 21 & 07 & YES & 5,1 & 0000101100011100 & $\ldots$ & 0000101100011100 \\
\hline 22 & 22 & YES & 5,1 & 1100001011000111 & 15 & 1100001011000111 \\
\hline 23 & 28 & YES & 7,15 & 1111000110010110 & $\ldots$ & 1111000110010110 \\
\hline 24 & 26 & YES & 7,15 & 0100101100011001 & 1 & 1100101100011001 \\
\hline 25 & 17 & YES & 9,6 & 1010010010101111 & $\ldots$ & 1010010010101111 \\
\hline 26 & 10 & YES & 9,6 & 1110000110101011 & $\ldots$ & 1110000110101011 \\
\hline 27 & 30 & No & $\ldots$ & 1010111001100110 & $\ldots$ & 1010111001100110 \\
\hline 28 & 23 & YES & 8,10 & 0100111101000110 & 12,13 & 0100111101011110 \\
\hline 29 & 19 & YES & 8,10 & 0110100111100110 & 6,12 & 0110110111110110 \\
\hline 30 & 19 & No & $\ldots$ & 0110100101100110 & $\ldots$ & 0110100101100110 \\
\hline
\end{tabular}

The third operator, mutation, was then applied on the intermediate population. Bit-wise mutation was performed. The mutation operator changes 1 to 0 and vice versa based on a small mutation probability, pm. Mutation was implemented with the probability of 0.1 as shown in Table 6.10. Mutation is basically intended for local search around the current solution. Implementation of mutation completes one iteration of the algorithm. The above procedure was epeated until the maximum number of generations was completed. For better convergence, the algorithm was run for the maximum of 200 generations. Hence from the usual binary tournament selection, recombination, and mutation operators are used to create a child population Qt of size 30. This population is shown in table 5.11.
Table.5.11.NEW POPULATION

\begin{tabular}{|c|c|c|c|c|c|c|}
\hline S.10 & $\mathrm{XI}$ & $X$ & $X 3$ & XA & $\begin{array}{c}\mathrm{Ra}_{\mathrm{a}} \\
(\mathrm{um})\end{array}$ & $\begin{array}{l}\text { MI } \\
(\mathrm{min})\end{array}$ \\
\hline 1 & 7600 & 1713.55 & 0.10 & 3.86 & 0.4585 & 0.9670 \\
\hline 2 & 4400 & 4800.00 & 0.26 & 5.00 & 1.3685 & 1.5957 \\
\hline 3 & 4000 & 3458.06 & 0.53 & 5.00 & 2.5852 & 0.8617 \\
\hline 4 & 5200 & 2787.09 & 0.74 & 2.14 & 1.8202 & 1.6277 \\
\hline$j$ & 7200 & 1042.58 & 0.26 & 2.14 & 0.6562 & 2.8170 \\
\hline 6 & 8800 & 4129.03 & 0.37 & 5.00 & 0.9667 & 0.6322 \\
\hline 7 & 4400 & 3864.64 & 0.53 & 5.00 & 2.4706 & 1.0280 \\
\hline 8 & 8800 & 3055.48 & 0.42 & 2.71 & 1.1869 & 1.0378 \\
\hline 9 & 8000 & 2787.09 & 0.85 & 2.71 & 1.8471 & 1.1317 \\
\hline 10 & 8000 & 4397.41 & 0.53 & 4.43 & 1.6988 & 0.8757 \\
\hline 11 & 4000 & 3458.06 & 0.74 & 5.00 & 3.3248 & 0.7707 \\
\hline 12 & 10000 & 3189.67 & 0.10 & 2.14 & 0.8006 & 0.9887 \\
\hline 13 & 6400 & 3994.84 & 0.63 & 4.43 & 2.1548 & 0.8915 \\
\hline 14 & 5600 & 3189.68 & 0.31 & 5.00 & 1.1104 & 0.8066 \\
\hline 15 & 8800 & 774.19 & 0.85 & 2.71 & 0.8643 & 2.5468 \\
\hline 16 & 9600 & 1847.74 & 0.37 & 2.71 & 1.1294 & 1.4622 \\
\hline 17 & 5200 & 3458.06 & 0.26 & 3.28 & 1.0224 & 0.8988 \\
\hline 18 & 4400 & 4665.81 & 0.58 & 5.00 & 2.8778 & 1.5213 \\
\hline 19 & 4000 & 3458.06 & 0.53 & 5.00 & 2.5852 & 0.8617 \\
\hline 20 & 5600 & 3189.68 & 0.31 & 5.00 & 1.1104 & 0.8066 \\
\hline 21 & 4000 & 3592.26 & 0.26 & 3.28 & 1.4210 & 0.0690 \\
\hline 22 & 8800 & 1310.97 & 0.53 & 5.00 & 0.8752 & 1.2477 \\
\hline 23 & 10000 & 1042.58 & 0.21 & 4.43 & 0.8018 & 1.1669 \\
\hline 24 & 8800 & 3592.26 & 0.26 & 1.57 & 0.7430 & 1.9170 \\
\hline 25 & 8000 & 1847.74 & 0.37 & 5.00 & 0.7381 & 0.9465 \\
\hline 26 & 9600 & 1042.58 & 0.37 & 2.71 & 1.0535 & 2.2070 \\
\hline 27 & 8000 & 4397.42 & 0.74 & 4.43 & 2.4828 & 0.8398 \\
\hline 28 & 5600 & 4660.81 & 0.69 & 4.43 & 28381 & 1.3008 \\
\hline 29 & 6400 & 4263.22 & 0.85 & 4.43 & 3.0584 & 0.9034 \\
\hline 30 & 6400 & 3055.48 & 0.74 & 4.43 & 2.1535 & 0.6583 \\
\hline
\end{tabular}

Now, we combined the parent population $\mathrm{P} t$ and child population $\mathrm{Q} t$ to get $\mathrm{Rt}(\operatorname{as} \mathrm{R} \mathrm{t}=\mathrm{Pt} \square \mathrm{Qt})$. The population Rt will be of size 60. Then, the population Rt is sorted according to non-domination as discussed above. Since all previous and current population members are included in Rt, the elitism is ensured. Now, solutions belonging to the best non-dominated first set F1 are 9,11,13,14,15,16,28,41, 48,52 of best solutions in the combined population and must be emphasized more than any other solution in the combined 
population. Here the size of F1 is 10 , which is smaller than 27, we definitely choose all members of the set F1 for the new population $\mathrm{Pt}+1$. The remaining members of the population $\mathrm{Pt}+1$ are chosen from subsequent non-dominated fronts in the order of their ranking. Thus, solutions from the second set F2 are 19, 34, 35, 36, 38, 42, 45, 47 and 53 of size 9 chosen. Next, followed by solutions from the third set F3 are $10,22,24,26,29,30,32,43,50$ and 51 of size 10 .Now, the count of solutions in all sets from F1 to F3 of 29 would be larger than the population size of 27. To choose exactly 27 population members, we sort the solutions of the last front i.e., from F3 using the crowded comparison operator $\square \mathrm{n}$, in the descending order and choose the best solutions needed to fill all population slots as shown in Table 5.11 .

\section{RESU LTS}

\begin{tabular}{|c|c|c|c|c|c|c|}
\hline S.NO & $\mathrm{X} 1$ & $\mathrm{X} 2$ & $\mathrm{X} 3$ & $\mathrm{X} 4$ & $\begin{array}{c}\mathrm{Ra} \\
(\mathrm{mm})\end{array}$ & $\begin{array}{c}\mathrm{MT} \\
(\mathrm{min})\end{array}$ \\
\hline 1 & 6533.187 & 2439.51 & 0.100076 & 1.000004 & 0.084051 & 2.931112 \\
\hline 2 & 6508.645 & 2002.209 & 0.100049 & 1.000017 & 0.156272 & 3.183431 \\
\hline 3 & 6466.435 & 1249.54 & 0.100004 & 1.000011 & 0.283715 & 3.811783 \\
\hline 4 & 6448.678 & 2192.7 & 0.10002 & 1.000007 & 0.123591 & 3.062107 \\
\hline 5 & 6480.476 & 2174.824 & 0.100132 & 1.000008 & 0.127108 & 3.073385 \\
\hline 6 & 6406.645 & 2138.849 & 0.100017 & 1.000019 & 0.132289 & 3.093435 \\
\hline 7 & 6447.739 & 1011.441 & 0.100512 & 1.000018 & 0.325055 & 4.06183 \\
\hline 8 & 6430.935 & 1069.701 & 0.100062 & 1.000005 & 0.31475 & 3.996808 \\
\hline 9 & 6485.049 & 1004.334 & 0.100026 & 1.000016 & 0.326229 & 4.071477 \\
\hline 10 & 6466.309 & 926.4827 & 0.100079 & 1.000058 & 0.339711 & 4.157937 \\
\hline 11 & 6442.314 & 1738.919 & 0.100273 & 1.000044 & 0.200194 & 3.37376 \\
\hline 12 & 6413.774 & 1657.177 & 0.100011 & 1.00001 & 0.213694 & 3.438123 \\
\hline 13 & 6435.172 & 1385.096 & 0.100049 & & 0.260304 & 3.678696 \\
\hline 14 & 6402.46 & 2756.851 & 0.100018 & 1.000004 & 0.029757 & 2.800237 \\
\hline 15 & 6403.286 & 1974.26 & 0.100053 & 1.000015 & 0.159988 & 3.199643 \\
\hline 16 & 6436.883 & 1465.12 & 0.100004 & 1.000014 & 0.246556 & 3.604857 \\
\hline 17 & 6450.108 & 1631.655 & 0.10046 & 1.000047 & 0.218621 & 3.461059 \\
\hline 18 & 6468.069 & 1541.808 & 0.100008 & 1.000053 & 0.233632 & 3.537966 \\
\hline 19 & 6442.314 & 1910.555 & 0.100304 & 1.000074 & 0.171245 & 3.24531 \\
\hline 20 & 6445.05 & 775.8321 & 0.100009 & 1.000004 & 0.365961 & 4.333501 \\
\hline
\end{tabular}

\begin{tabular}{|c|c|c|c|c|c|c|}
\hline 21 & 620.87 & COR.4053 & 0.10053 & 1.00008 & 0.36069 & 4.295 \\
\hline 2 & 6461.528 & 225998 & 0.10282 & 1.00042 & 0.03604 & 2811168 \\
\hline 2 & 6435.23 & 163275 & 0.10013 & 1.0001 & 0.214545 & 3.442301 \\
\hline 24 & 6278611 & 1086794 & 0.10006 & 1.00115 & 0.313179 & 396860 \\
\hline 25 & 6627.468 & 1277.514 & 0.10153 & 1.0004 & 0.28132 & 3791.42 \\
\hline 26 & 62832 & 2665.57 & 0.10061 & 1.00001 & 0.04660 & 2.82798 \\
\hline 27 & 649.948 & 1373.88 & 0.10104 & 1.0001 & 0.26265 & 3690516 \\
\hline $\bar{R}$ & 640.63 & 910.403 & 0.10011 & 1.0001 & 0.24215 & 4.17211 \\
\hline 79 & 6993.53 & 1184.624 & 0.10077 & 1.0005 & 0.294911 & 387363 \\
\hline 30 & 64559 & 129,08 & 0.10031 & 1.0002 & 0.28725 & 3.8318 \\
\hline 31 & 6481.84 & 112.661 & 0.100121 & 1.0041 & 0.305767 & 394321 \\
\hline 32 & 6410.315 & 239.466 & 0.10071 & 1.0013 & 0.08012 & 294924 \\
\hline 33 & 647328 & 1686.096 & 0.100248 & 1.00049 & 0.209375 & 3.41705 \\
\hline 34 & 6474.423 & 2881.491 & 0.100021 & 1.0001 & 0.010346 & 2.76096 \\
\hline 35 & 6464.141 & 134606 & 0.10015 & 1.00027 & 0.267111 & 371709 \\
\hline 36 & 648.078 & 201812 & 0.10133 & 1.0003 & 0.15334 & 3.17246 \\
\hline 37 & 645.564 & 2694.278 & 0.10015 & 1.0003 & 0.040934 & 28292 \\
\hline 38 & 6443.67 & 2467.46 & 0.10024 & 1.00015 & 0.07782 & 2.91712 \\
\hline 39 & 62839 & 887814 & 0.1002 & 1.00015 & 0.35079 & 4.27668 \\
\hline 40 & 6432301 & 1714.67 & 0.10023 & 1.0015 & 0.203989 & 3.39262 \\
\hline 41 & 647.88 & 236.301 & 0.10334 & 1.0016 & 0.097162 & 2972445 \\
\hline 42 & 6476.37 & 1168119 & 0.10066 & 1.0016 & 0.29748 & 3.89317 \\
\hline 43 & 647.401 & 2464.50 & 0.10024 & 1.00018 & 0.07902 & 291917 \\
\hline 44 & 6440.68 & 104302 & 0.10033 & 1.0006 & 0.31908 & 4.024101 \\
\hline 45 & 6420.88 & 715692 & 0.10013 & 1.0002 & 0.37666 & 4.405141 \\
\hline
\end{tabular}




\begin{tabular}{|c|c|c|c|c|c|c|}
\hline 46 & 6417.316 & 2059.24 & 0.100008 & 1.000005 & 0.145687 & 3.14364 \\
\hline 47 & 6436.601 & 1425.448 & 0.100133 & 1.000018 & 0.253453 & 3.641231 \\
\hline 48 & 6466.104 & 751.5437 & 0.1 & 1.000019 & 0.370228 & 4.364404 \\
\hline 49 & 6482.078 & 1962.534 & 0.100213 & 1.00003 & 0.162766 & 3.209974 \\
\hline 50 & 6466.151 & 1601.873 & 0.100054 & 1.000057 & 0.223422 & 3.486283 \\
\hline 51 & 6406.645 & 2079.996 & 0.100017 & 1.000019 & 0.142164 & 3.130072 \\
\hline 52 & 6383.798 & 2279.854 & 0.100008 & 1.000005 & 0.108594 & 3.011401 \\
\hline 53 & 6431.76 & 1496.802 & 0.10002 & 1.000006 & 0.241126 & 3.576187 \\
\hline 54 & 6468.34 & 817.7863 & 0.10007 & 1.000008 & 0.358655 & 4.28487 \\
\hline 55 & 6627.339 & 885.2525 & 0.100063 & 1.000027 & 0.348804 & 4.215125 \\
\hline 56 & 6448.678 & 2327.431 & 0.10002 & 1.000066 & 0.10116 & 2.98683 \\
\hline 57 & 6402.46 & 2782.552 & 0.10016 & 1.000017 & 0.025824 & 2.791793 \\
\hline 58 & 6430.935 & 1810.744 & 0.100062 & 1.000005 & 0.187731 & 3.317908 \\
\hline 59 & 6468.34 & 2903.07 & 0.100038 & 1.000004 & 0.006761 & 2.754963 \\
\hline 60 & 6463.568 & 1412.593 & 0.10002 & 1.000007 & 0.25569 & 3.654298 \\
\hline 61 & 6441.079 & 1849.989 & 0.100126 & 1.00009 & 0.181251 & 3.288922 \\
\hline 62 & 6407.021 & 2111.907 & 0.100017 & 1.000013 & 0.136808 & 3.110036 \\
\hline 63 & 6304.319 & 2162.031 & 0.100239 & 1.000005 & 0.128827 & 3.077055 \\
\hline 64 & 6465.309 & 984.3735 & 0.100055 & 1.000008 & 0.329617 & 4.092536 \\
\hline 65 & 6427.13 & 1582.654 & 0.10009 & 1.000017 & 0.226507 & 3.501128 \\
\hline 66 & 6537.083 & 2240.459 & 0.100092 & 1.000001 & 0.117094 & 3.035917 \\
\hline 67 & 6377.428 & 1702.305 & 0.10009 & 1.000008 & 0.206082 & 3.400176 \\
\hline 68 & 6413.774 & 1396.08 & 0.100003 & 1.00001 & 0.258357 & 3.667285 \\
\hline 69 & 6505.752 & 2832.963 & 0.100221 & 1.000042 & 0.019278 & 2.775395 \\
\hline 70 & 6466.151 & 2095.057 & 0.100054 & 1.000057 & 0.140164 & 3.121915 \\
\hline 71 & 6424.593 & 2645.315 & 0.100002 & 1.000004 & 0.04827 & 2.840871 \\
\hline 72 & 6530.755 & 711.3897 & 0.100013 & 1.000002 & 0.37759 & 4.41821 \\
\hline 73 & 6414.89 & 1634.362 & 0.100011 & 1.00001 & 0.217584 & 3.457004 \\
\hline 74 & 6370.479 & 2517.116 & $0.10009^{7}$ & 1.000002 & 0.069235 & 2.893842 \\
\hline 75 & 6419.938 & 961.4498 & 0.100012 & 1.000009 & 0.33357 & 4.115325 \\
\hline 76 & 6392.535 & 1097.991 & 0.100118 & 1.000013 & 0.309958 & 3.964201 \\
\hline 77 & 6442.314 & 1775.824 & 0.100304 & 1.000004 & 0.193967 & 3.345141 \\
\hline 78 & 6481.824 & 855.8771 & 0.100014 & 1.000003 & 0.352035 & 4.240701 \\
\hline 79 & 6458.705 & 1036.191 & 0.100095 & 1.00004 & 0.320625 & 4.034852 \\
\hline 80 & 6452.106 & 1136.049 & 0.100008 & 1.000004 & 0.303254 & 3.927393 \\
\hline
\end{tabular}

\begin{tabular}{|c|c|c|c|c|c|c|}
\hline 81 & 6468.069 & 1563.753 & 0.100025 & 1.000053 & 0.229904 & 3.51893 \\
\hline 82 & 6442.314 & 1945.871 & 0.100276 & 1.000044 & 0.165258 & 3.220494 \\
\hline 83 & 6461.528 & 2562.579 & 0.100176 & 1.000042 & 0.06267 & 2.874874 \\
\hline 84 & 6442.097 & 1932.713 & 0.100304 & 1.000016 & 0.167497 & 3.229741 \\
\hline 85 & 6463.089 & 936.9364 & 0.100004 & 1.000003 & 0.337842 & 4.145823 \\
\hline 86 & 6398.68 & 2915.108 & 0.100112 & 1.000008 & 0.004018 & 2.752153 \\
\hline$\overline{86}$ & "6398.68 & 2915.108 & 0.100112 & 1.000008 & 0.004018 & $\overline{2.752153}$ \\
\hline 87 & 6431.76 & 1758.918 & 0.100224 & 1.000006 & 0.196686 & 3.357763 \\
\hline 88 & 6462.436 & 1226.263 & 0.10002 & 1.000007 & 0.287716 & 3.835008 \\
\hline 89 & 6463.089 & 1203.677 & 0.100008 & 1.000003 & 0.291606 & 3.857981 \\
\hline 90 & 6440.692 & 1285.667 & 0.100017 & 1.000013 & 0.2774 & 3.774602 \\
\hline 91 & 6403.145 & 1477.991 & 0.100004 & 1.000054 & 0.244314 & 3.591619 \\
\hline 92 & 6450.854 & 1820.891 & 0.100142 & 1.000037 & 0.186238 & 3.310966 \\
\hline 93 & 6450.854 & 2504.056 & 0.100248 & 1.000037 & 0.072296 & 2.900568 \\
\hline 94 & 6464.211 & 1337.285 & 0.100101 & 1 & 0.268669 & 3.725651 \\
\hline 95 & 5549.974 & 4799.965 & 0.147509 & 1 & 0.08998 & 3.118402 \\
\hline 96 & 5551.665 & 4799.954 & 0.188925 & 1.000034 & 0.066586 & 3.156852 \\
\hline 97 & 5649.898 & 4799.998 & 0.212056 & 1 & 0.145376 & 3.174862 \\
\hline 98 & 5584.014 & 4799.995 & 0.203744 & 1 & 0.119541 & 3.169178 \\
\hline 99 & 5585.436 & 4799.991 & 0.185838 & 1 & 0.052121 & 3.153552 \\
\hline 100 & 5539.064 & 4799.998 & 0.173789 & 1 & 0.010529 & 3.14352 \\
\hline
\end{tabular}

The algorithm can be run for a few more times to get more number of optimal values. It can be observed from the table 7 , that no solution in the front is better than any other as they are non-dominated solutions. The choice of a solution has to be made based on the production requirements. Table 7 enables to choose the optimal machining parameters for a fixed combination of the metal removal rate and the surface roughness. The obtained values by the algorithm are better than the experimentally observed values shown in Table 6.3. For example, the 23rd experiment in Table 6.3 leads to the $\mathrm{Ra}$ value of $2.25 \mu \mathrm{m}$ and the MRR value of $4.242 \mathrm{gm} / \mathrm{min}$. By optimization using the proposed algorithm, for the same value of Ra, the MRR was increased to $7.6807 \mathrm{gm} / \mathrm{min}$ (S. No. 44, Table 7). Similarly, the 11th experiment from Table 6.3 corresponds to the Ra value of $1.65 \mu \mathrm{m}$ and the MRR of 3.088 $\mathrm{gm} / \mathrm{min}$. After optimization, the $\mathrm{Ra}$ was reduced to $1.49 \mu \mathrm{m}$, for approximately the same value of the MRR of 3.0883 $\mathrm{gm} / \mathrm{min}$ (S. No.40, from Table 7). In the above cases, improvement in the output responses was made possible by the selection of the different set of machining parameters. 


\section{CONCLUSIONS}

Optimization of end milling parameters is very much essential as this is a highly stochastic process. Optimization helps in determining the parameters that result in both improved production rate and enhanced surface quality. In the present work influences of end milling parameters namely Spindle speed, Feed Rate, Depth of cut, Step over on Surface roughness (Ra) and Machining time (MT) are studied. Analytical models are developed based on experimental results for Ra and MT using Response Surface Methodology (RSM). The present problem has been modeled as a multiobjective problem as Ra and MT are conflicting in nature. Increasing an input parameter in end milling results in improved production rate and increased tool wear as well. Excessive tool wear leads to poor surface quality. The optimization of these models is carried out using Nondominated Sorting Genetic Algorithm (NSGA). Unlike the conventional methods like Classical weighted approach and Goal programming method, NSGA retrieves all the Pareto-sets irrespective of the indicated weights of the objective functions. It is useful for the manufacturing industrie to select the values of input parameters at the desired levels of Ra and MT. Different sets of optimal process parameters are found out and represented in the form known as the Pareto-optimal set. Totally 100 such optimal parametric combinations are identified. The NSGA algorithm is implemented using Visual $\mathrm{C}++$.

In the Pareto-optimal set, the outcome is a group of nondominated solutions and none of the solution is better than any other solution in that set. Hence, a process engineer can select optimal combination of parameters from that set, depending upon the requirements. Once the optimal values have been determined the process can be automated based on those values.

\section{REFERENCES}

[1]. E.J.A. Armarego "Fundamental studies of driven and selfpropelled rotary tool cutting process"- theoretical investigation, July 1993.

[2]. Shuting Lei "High speed machining of titanium alloys using driven rotary tool". Journal of Manufacturing Tools and Science, January 2002.

[3]. P.G.Benardos "Predicting surface roughness in machining: a review".

International Journal of machine tools and manufacture, December 2002.

[4]. Yusuf Sahin "Surface roughness model for machining mild steel". Materials and design, May 2004.

[5]. R.K.Katta "Predictive cutting model for forces and power in self-propelled rotary tool turning operations". January 1997. 